\title{
Microencapsulation of microbial antioxidants from Mucor circinelloides, their physico-chemical characterization, in vitro digestion and releasing behaviors in food
}

\author{
Ahsan Hameed ${ }^{1,2+}$ (D), Syed Ammar Hussain 1,3† , Shaista Nosheen ${ }^{1}$, Zafarullah Muhammad ${ }^{4}$, Yang Wu$^{1}$, \\ Samee Ullah', Hafiz Ansar Rasul Suleria ${ }^{5,6,7}$ and Yuanda Song ${ }^{1 *}$
}

\begin{abstract}
This study aimed at increasing the stability of heat-labile and $\mathrm{pH}$-sensitive microbial antioxidants by the microencapsulation. Microbial antioxidants from Mucor circinelloides were microencapsulated. The physico-chemical and powder flowing properties of resulting microcapsules were evaluated. The initial safety studies were evaluated by in vivo acute oral toxicity tests. The bio-accessibility of powders vs. extracts was analyzed in in vitro digestion models with further application of microcapsules to model food system. Physico-chemical properties were significantly different $(p<0.0001)$ for all microcapsules regardless of their non-substantial variations $(p>0.05)$ in powder flowing properties. The microencapsulation of extract with $5 \%$ whey protein hydrogels $(\mathrm{WPHG})+5 \%$ pectin $\left(\mathrm{T}_{\mathrm{A}}\right)$ showed higher retain-ability of polyphenols accompanying low degradation in gastric and intestinal digestion and with no major toxicity signs. The addition of $\mathrm{T}_{\mathrm{A}}$ microcapsule did not produce any nutritional, physico-chemical, compositional, and nutritional distinctions in cheese. Microencapsulation proved to be appropriate approach for not only protecting the thermo-labile and pH-sensitive microbial antioxidants but also for enhanced bioavailability, and targeted release of bioactive extracts.
\end{abstract}

Keywords: Microbial antioxidants, Microencapsulation, Freeze drying, Cottage cheese, Mucor circinelloides, Release behavior

\section{Introduction}

The concept of "microbial antioxidants" was first time presented in literature by our previous works in which microbial production of antioxidants was carried out by exploiting the three important oleaginous strains of filamentous fungi called as Mucor circinelloides (MC) [22, 23]. These three important strains were MC CBS 277.49

\footnotetext{
*Correspondence: ysong@sdut.edu.cn; ysong@jiangnan.edu.cn ${ }^{\dagger}$ Ahsan Hameed and Syed Ammar Hussain contributed equally to this work and are equal first authors

${ }^{1}$ Colin Ratledge Center for Microbial Lipids, School of Agriculture Engineering and Food Science, Shandong University of Technology, Zibo, People's Republic of China

Full list of author information is available at the end of the article
}

(MCCBS277.49), MC CBS 108.48 (MCCBS108.48), and MC WJ11 (MCWJ11). This work exceptionally declared the candidacy of two strains of MC (i.e., MCCBS 277.49 and MCWJ11) for the microbial production of antioxidants with their possible applications in food and pharmaceutical industry. MC is considered a true "microbial factory" due to its inherent capability of microbial production of organic acids, enzymes, lipids, ethanol, food colorants ( $\beta$-carotene and lycopene), essential amino acids, chitin, chitosan, and polyphenolic antioxidants [22, 23]. Polyphenols were the major antioxidant components in the mycelia extracts of MC [23]. The characterization of these polyphenolic rich extracts of identified polyphenolic compounds majorly belonging to lipid amides, 
alkaloids, pigments, benzoic acids, terpenoids, cinnamic acid, benzopyrans etc. classes of polyphenolic compounds [22].

The storage and stability studies under accelerated processing conditions and biological buffers mimicking the human fluids revealed the $\mathrm{pH}$-sensitivity, and thermo-labile nature of these polyphenolic antioxidants [22]. The degradation of these microbial antioxidant compounds may hinder the potential effectiveness of these microbial antioxidants in food/nutraceutical and pharmaceutical applications. To overcome these limitations and to increase the stability of antioxidants, and protect their (bio)functionalities, microencapsulation has been exploited as a trustworthy technique to avert the undesirable annihilation of bioactive compounds. The microencapsulation of microbial secondary metabolites may not only preserve and stabilize the antioxidants but also can improve the retention time of antioxidants with improved bio-digestibility/bio-accessibility, offer controlled and targeted release, hinder the adverse interactions among food matrices and bioactive compounds, and masking the astringent taste and smell of bioactive compounds [3].

Now a days, various sophisticated (bio-functional) wall materials and microencapsulation techniques have been developed. The microcapsules produced by each method are different [17]. From the available microencapsulation techniques, the freeze-drying approach was selected for microencapsulation, despite of its high input cost, to further limit the possibilities of antioxidant degradation. Furthermore, the material for encapsulation possesses equal significance like the way encapsulation executed. Among the numerous, commonly employed wall materials for encapsulating the polyphenols rich extracts, pectin, partially hydrolyzed guar gum (PHGG), and whey protein hydrogels (WPHG) are one of them. The plant based polysaccharide known as pectin possess robust film forming, binding, and effective emulsion stabilizer properties. Pectin is also resistant to digestive enzyme, and, hence, used to attain the exact spot of specific delivery of bioactive compounds due to its $\mathrm{pH}$-dependent delivery system and $\mathrm{pH}$-sensitive behavior [53]. Moreover, the approach of controlled/partial enzymatic hydrolysis of guar gum is used to produce PHGG. PHGG is less viscous, low molecular weight, stable, odorless, tasteless, low water holding capable biopolymer with varying solubility features across the wide range of $\mathrm{pH}$ [28]. PHGG is least studied functional biopolymer as a wall material but it does provide additional health gains with respect to minimum bio-accessibility of fat and cholesterol in gut [36]. WPHG is heat tempted whey protein gel with preferred $\mathrm{pH}$-predisposition, oriented permeability, and mechanical characteristics. WPHG is another potential good biodegradable carrier of bioactive compounds for site-specific and controlled release of bioactive compounds without any further chemical/enzymatic treatment [21]. However, despite the good and dynamic wall features, an encapsulating material hardly offers all the desires encapsulating characteristics. Thus, the use of mixture of two encapsulating biopolymers is the ultimate way to further widen the efficiency of encapsulation.

Following microencapsulation, appraisal of stability of resulting microcapsule powders during in vitro gastrointestinal conditions and in oil-in-water emulsion system (i.e. cottage cheese) was conducted and compared with non-microencapsulated extracts. Simulated in vitro digestion model was selected for control release studies as these kinds of models are cheap, easy to perform without the need of any high-tech equipment. Additionally, in simulated in vitro digestion models, bio-accessibility of lipophilic or hydrophilic phytochemicals can be assessed by simple centrifugation [35] centrifugation/filtration (through $0.2 \mu \mathrm{m}$ or even $0.02 \mu \mathrm{m}$ filters) [29], or, alternatively, following diffusion through semipermeable membranes (dialysis), with e.g. 10,000-12,000 Da cut-offs [8]. For application of powders, oil-in-water $(\mathrm{o} / \mathrm{w})$ emulsion system selected. Various food products represent the oilin-water $(\mathrm{o} / \mathrm{w})$ emulsion systems i.e. mayonnaise, (coconut)yoghurt, butter, cheese etc. However, cottage cheese was used, as most of studies in literature described the effect of antioxidants in simple o/w system whereas studies dealing with real o/w systems are rare [26]. In short, the objective of current report was to microencapsulate microbial antioxidant rich extract from MCWJ11 and studied the physico-chemical, powder-flowing, in vitro bio-digestibility/bio-accessibility of consequent microcapsules. Last but not least, toxicity, palatability, nutritional and chromatic appraisal of the cottage cheese with added free and microencapsulated powder was also executed along consumer liking data.

\section{Materials and methods Chemicals, solvents and other reagents}

All the (bio)chemicals materials, solvents or reagents utilized in this work were of biological/spectroscopic/ analytical grade or otherwise higher where appropriate. Anhydrous, 2, 2-diphenyl-1-picrylhydrazyl (DPPH), anhydrous monobasic potassium phosphate, Foline Ciocalteu (FC) reagent, aluminum chloride, gallic acid, sodium nitrite, sodium hydroxide, sodium carbonate anhydrous, anhydrous ascorbic acid, trichloroacetic acid, ferric chloride, sulfuric acid, potassium-hexacyanoferrate, and catechin were procured from Sigma-Aldrich $\mathrm{GmbH}$ (Sternheim, Germany) whereas analytical-grade methanol, acetonitrile ethanol, potassium sorbate (E202), and acetone were provided by Sigma-Aldrich (St. Louis, 
MO, USA). Ciocalteu reagent, pancreatin, 2, 20-azobisamidinopropane (ABAP), pepsin and dichlorofluorescein diacetate (DCFH-DA) were attained from Sigma (St. Louis, U.S.). Highly-pure water $(18 \mathrm{M} \Omega / \mathrm{cm})$ was attained from Milli-Q purification device (Millipore Co. USA). Sodium hydrogen carbonate was purchased from Merck (Germany). Sea sand with the grain size of 200300 was supplied by Scharlau (Barcelona, Spain). Microencapsulating material used was whey protein hydrogels (WPHG), pectin, and partially hydrolyzed guar gum (PHGG) supplied by a local manufacturing company (Guangzhou Zio Chemical Company Ltd., PR China).

\section{Strain and culture conditions}

The filamentous fungi $M$. circinelloides strain WJ11 (MCWJ11) isolated from soil at Jiangnan University (Wuxi, Jiangsu, PR China) and kindly provided by Dr. Xin Tang, State Key Laboratory of Food Science and Technology, School of Food Science and Technology, Jiangnan University, Wuxi, Jiangsu, PR China, was grown on solid agar Kendrick and Ratledge (K \& R) media for 5 days at $28 \pm 2{ }^{\circ} \mathrm{C}$ to harvest spores. Aliquots of $100 \mu \mathrm{L}$ of freshly harvested spore suspensions $\left(10^{7}\right.$ spores $\left./ \mathrm{mL}\right)$ of high lipid producing filamentous fungus MCWJ11 were measured spectrophotometrically and inoculated into liquid $\mathrm{K}$ and $\mathrm{R}$ medium $(150 \mathrm{~mL}$ ) held in $1 \mathrm{~L}$ flasks having baffles (New Brunswick Scientific, Co., Ltd., Edison, NJ, USA) to improve aeration [23] and incubated overnight at $30{ }^{\circ} \mathrm{C}$ with $150 \mathrm{rpm}$ shaking. The $\mathrm{K}$ and $\mathrm{R}$ medium contained $3.3 \mathrm{~g} / \mathrm{L}$ diammonium tartrate, $30 \mathrm{~g} / \mathrm{L}$ glucose, $2.0 \mathrm{~g} / \mathrm{L} \mathrm{Na}{ }_{2} \mathrm{HPO}_{4}, 7.0 \mathrm{~g} / \mathrm{L} \mathrm{KH}_{2} \mathrm{PO}_{4}, 1.5 \mathrm{~g} / \mathrm{L}$ yeast extract (Saccharomyces cerevisiae), $1.5 \mathrm{~g} / \mathrm{L} \mathrm{MgSO}_{4} \cdot 7 \mathrm{H}_{2} \mathrm{O}$, $8 \mathrm{mg} / \mathrm{L} \mathrm{FeC1} 1_{3} \cdot 6 \mathrm{H}_{2} \mathrm{O}, 0.1 \mathrm{mg} / \mathrm{L} \mathrm{CaC1} 1_{2} \cdot 2 \mathrm{H}_{2} \mathrm{O}, 0.1 \mathrm{mg} / \mathrm{L}$ $\mathrm{CuSO}_{4} \cdot 5 \mathrm{H}_{2} \mathrm{O}, \quad 1 \mathrm{mg} / \mathrm{L} \quad \mathrm{ZnSO}_{4} \cdot 7 \mathrm{H}_{2} \mathrm{O}, \quad 0.1 \mathrm{mg} / \mathrm{L}$ $\mathrm{MnSO}_{4} \cdot 5 \mathrm{H}_{2} \mathrm{O}$ and $0.1 \mathrm{mg} / \mathrm{L} \mathrm{CO}\left(\mathrm{NO}_{3}\right) \cdot 6 \mathrm{H}_{2} \mathrm{O}, \mathrm{pH}$ 6.0. Fermenters (2 L; BioFlo/CelliGen-310/115, New Brunswick Scientific, Co.) containing $1.5 \mathrm{~L}$ modified $\mathrm{K}$ and $\mathrm{R}$ medium ( $2 \mathrm{~g}$ diammonium tartrate, $80 \mathrm{~g}$ glucose/L plus the inorganic salts, as listed above, were used to incubate $10 \%(\mathrm{v} / \mathrm{v})$ overnight cultures for inoculation for $120 \mathrm{~h}$ in the $2 \mathrm{~L}$ fermenters. The modified $\mathrm{K}$ and $\mathrm{R}$ medium has 2.5 folds higher glucose with $90 \%$ reduction in $\mathrm{N} 2$ and $\mathrm{P}$. The $\mathrm{pH}$ was maintained at 6.0 by auto-addition of $2 \mathrm{M}$ $\mathrm{H}_{2} \mathrm{SO}_{4}$ or $4 \mathrm{M} \mathrm{KOH}[23,24,30]$.

\section{Preparation of extracts by pressurized liquid extraction (PLEx)}

After 5 days of fermentation using the physiological stress medium, the mycelia were collected using filtration through single layer of muslin cloth, washed thrice with Milli-Q water (Milli-Q Ultrapure Lab-water System, Merck Millipore, Co., Darmstadt, Germany), lyophilized (6 L FreeZone Freeze Dryer, Labconco Corp., Ltd., Kansas
City, MO, USA) and pulverized (HC-350 Damai grinder, Yongkang Tianqi Shengshi Industry and Trade Co., Pvt., Ltd., Hangzhou, Zhejiang, PR China) in the presence of liquid nitrogen until finely powdered and screened $(1.0 \mathrm{~mm})$. The pressurized liquid extraction (PLEx) was done in a Dionex ASE 350 system (Dionex, Sunnyvale, CA, USA) from the initial lyophilized mycelia. Aliquots of $5 \mathrm{~g}$ of lyophilized filamentous fungi were mixed with diatomaceous earth (1:1) (Qingdao Tuosheng Diatomite Co. Ltd., Qingdao, Shandong, PR China) and placed in $34 \mathrm{~mL}$ stainless steel cells (Dionex ${ }^{\mathrm{TM}} \mathrm{ASE}^{\mathrm{TM}}$ 150/350, Dionex). The extraction was done in triplicate with absolute ethanol with the following conditions: $t=15 \mathrm{~min}$ extraction time, $10.3 \mathrm{MPa}$ at $70{ }^{\circ} \mathrm{C}$. Organic solvent was evaporated at $40{ }^{\circ} \mathrm{C}$ in a rotary vacuum evaporator, while the remaining moisture/water was removed using lyophilization [24]. During solvent evaporization, the extracts were kept under nitrogen 20-30 min and kept in screwcapped amber-colored glass bottles at $-80{ }^{\circ} \mathrm{C}$ until analyzed in duplicate, for a maximum of 12 weeks.

\section{Microencapsulation powders preparation}

In order to formulate the specific dispersions, lyophilized microbial extracts $(1.5 \mathrm{~g})$ were diluted with (Milli-Q) water $(100 \mathrm{~mL})$ (Milli-Q Ultrapure Lab-water System, Merck Millipore, Co., Darmstadt, Germany) and these "1.5\% (w/v) aqueous extracts" were further mixed (GS585-worktop multifunctional vacuum blender, Shanghai Guosheng Industrial Co., Ltd., Shanghai, PR, China) independently with pre-selected wall materials $(10 \% \mathrm{w} / \mathrm{v})$ as follow: $5 \%$ WPHG $+5 \%$ pectin $(\mathrm{w} / \mathrm{w})$ (henceforth denoted and discussed as TA), 10\% WPHG (henceforth denoted and discussed as $\mathrm{T}_{\mathrm{B}}$ ), (5\% PHGG and $5 \%$ pectin) (w/w) (henceforth denoted and discussed as $\mathrm{T}_{\mathrm{C}}$ ), and (10\% of PHGG) (henceforth denoted and discussed as $\mathrm{T}_{\mathrm{D}}$ ). The above four sets of dispersions (10 g each) were rotated at $7500 \mathrm{rpm}$ for $7 \mathrm{~min}$ using an Ultra-Turrax (T25, IKA) individually and successively lyophilized using Alpha 1-4 LD plus freeze-drying unit (Labconco, Germany). For freeze-drying, the four dispersions initially freeze at $-80{ }^{\circ} \mathrm{C}$ for $24 \mathrm{~h}$ and followed by drying in the above-mentioned freeze-drying unit at $-70{ }^{\circ} \mathrm{C}$ at vacuum pressure less than $25 \mu \mathrm{mHg}$ for $96 \mathrm{~h}$. After this, the microencapsulated material was crumpled with mortar and pestle. A fine and uniform crumpled powder was collected by using a mesh of size $\leq 8 \mathrm{~mm}$. This uniformed size crumpled microencapsulated powder from four treatments were instantly placed in dark colored polyethylene bags and placed in aluminum sacks. The aluminum pounches were deposited in a desiccator comprising silica for additional analyses, which were executed in triplicate. 


\section{Physico-chemical properties of microencapsulated powders}

Moisture contents were determined according to the method of AOAC [4] (No. 943.06, section 37.1.10B). Briefly, following heating at $105^{\circ} \mathrm{C}$ in drying oven, weight loss of samples was noted. Water activity $\left(\mathrm{A}_{\mathrm{w}}\right)$ was calculated by undeviating readings in an electronic meter (Aqualab Dew Point $4 \mathrm{TEV}$ ) at $25{ }^{\circ} \mathrm{C}$ for $15 \mathrm{~min}$, after samples were stabilized. Solubility of microencapsulated powders was calculated conferring to method adopted from Cano-Chauca et al. [10], with some variations. Aliquot $1 \mathrm{~g}$ of powder from each treatment was mixed with $100 \mathrm{~mL}$ of deionized and distilled water tailed by stirring in a magnetic stirrer for at least $40 \mathrm{~min}$. Following, the solution was centrifuged at $9000 \mathrm{rpm}$ (Centrifuge 5810/5810R, Eppendorf AG, Hamburg, Germany) for $7 \mathrm{~min}$. Carefully, the supernatant $(25 \mathrm{~mL})$ was transferred to Petri dish of known weight and oven-dried instantly at $105{ }^{\circ} \mathrm{C}$ for $4-5 \mathrm{~h}$. The solubility was measured by difference of weight and expressed in percentage (\%). Hygroscopicity of powders was measured rendering to the technique dictated from Cai and Corke [9]. Briefly, aliquot $1 \mathrm{~g}$ of microcapsule powder was dried at $25^{\circ} \mathrm{C}$ with $\mathrm{NaCl}$ saturated solution (75.3\%). After 7 days, the hygroscopicity was articulated in percentage (\%) of adsorbed moisture by weighing the samples.

Differential scanning calorimetry (DSC) (DSC Q2000, TA Instruments, New Castle, DE) was employed to calculate the Glass transition temperature (Tg) of microcapsules. Aliquot $8 \mathrm{mg}$ of sample in aluminum was placed enclosed pans (Tzero, TA Instruments), whereas empty $\mathrm{Al}$ (aluminum) pan was taken as standard. The ultra-pure nitrogen was purge gas (flow $45-50 \mathrm{~mL} / \mathrm{min}$ ) with $70{ }^{\circ} \mathrm{C}$ to $120^{\circ} \mathrm{C}$ temperature range at a heating rate of $30{ }^{\circ} \mathrm{C} / \mathrm{min}$. The Tg values were measured using the TA Universal Analysis version 5.5 software. Morphology and particle size of uniform sized crumpled microencapsulated powder manufactured with various wall materials was examined in scanning electron microscope (SEM) (QUANTA-250, FEG Co., Holland), conferring to method of Shui and Leong [45]. There are many methods to determine the size and size distribution i.e. dynamic light scattering (DLS), microscopy, SEM etc. SEM uses a high energy beam of electrons $(20-30 \mathrm{keV})$ to create an image with higher magnification $(>100,000 \times)$ and resolution capabilities (down to $10 \mathrm{~nm}$ ) than optical microscopy. The technique has seen widespread use in size analysis of microcapsules [7]. Therefore, the surface morphology and particle size distribution pattern of microcapsules was observed by SEM. Powder particles were attached to an aluminum stub with double-sided sticky tape. The specimens were sputter coated with gold in an ionic sputter coater (SCD-005, BAL-TEC Co., England).
They were viewed and photographed in the SEM at an accelerating voltage of $10 \mathrm{kV}$. Examinations were made at $500 \times$ magnifications. The particle size distribution and average particle size examination were accomplished using Image (NIH, Bethesda, MD), where 50-200 microparticles were calculated discretely from the micrographs of SEM. The average particle size/diameter/span was described in $\mu \mathrm{m}$.

\section{Flow properties of microcapsules}

Bulk density, percentage compressibility, angle of repose, particle density, and tapped density were calculated. Toluene was used as a reference to measure the particle density by a pycnometric method. The measured particle density defined as the total mass of particle per its total volume. Graduated glass cylinder $(25 \mathrm{~mL})$ was used to determine the Bulk density of ten grams of loosely weighed powder. The initial/original volume $\left(V_{0}\right)$ was noted and which divided the sample weight to calculate bulk density. The "Tappin" approach was used to determine the compact density [15]. The probe is smash on the plane surface area to volume constant. The weight of the sample is divided by the final volume $\left(V_{f}\right)$ taken by the sample to measure compact density. The ration of compression is employed to measure the percentage compressibility and the Hausner ratio is measured with the relation

$$
H r=V 0 / V f \text {. }
$$

For the angle of repose test, $5 \mathrm{~g}$ of powder was used to determine angle of repose which was added to a flat surface via a dropping funnel located at $10 \mathrm{~cm}$ of that flat surface, impeding the withdrawal there from. Afterwards, the height $(\mathrm{h})$ and the radius ( $\mathrm{r}$ ) of the cone formed was determined by the tangent of the angle given by $h / r$ ratio [20]. The microencapsulation yield was determined based on the preservation of the total phenolic contents (TPC) after the microencapsulation [39]. For this, TPC of raw extracts used for microencapsulation and TPC of microcapsules-drawnextracts were measured according to method described below. For calculating the TPC of microcapsules-drawnextracts, microcapsules were extracted using the method of Cilek et al. [12] with some adjustments. Concisely, an aliquote sample $(100 \mathrm{mg})$ of each powder was disseminated for $3 \mathrm{~min}$ in ethanol ( $5 \mathrm{~mL}$ ) with subsequent filtration using microfilter $(0.45 \mu \mathrm{m})$ and TPC was recorded by spectrophotometer (Shimadzu Corp., Ltd., Kyoto). The equation for calculating the microencapsulation yield is as follows

$$
\begin{aligned}
& \text { Microencapsulation yield (\%) } \\
& =[1-\text { TPC of microcapsules-drawn-extracts } / \\
& \text { TPC of raw extracts }] * 100 .
\end{aligned}
$$




\section{Determination of bioactive compounds and their bioactivities after microencapsulation}

The three important microbial antioxidant components measured were total phenolic content (TPC), total flavonoid content (TFC) and total condensed tannins (TCT). The TPC of mycelium extracts $(5 \mathrm{mg} / \mathrm{mL})$ was measured by adopting a spectrophotometric (UV-1800 Spectrophotometer, Shimadzu Corp., Kyoto, Japan) method as described in Julkunen-tiitto [27] and Slinkard and Singletod [47]. Briefly, sample extracts $(250 \mu \mathrm{L})$ were mixed with $250 \mu \mathrm{L}$ of $10 \%(\mathrm{v} / \mathrm{v})$ FC reagent, followed by the addition of $500 \mu \mathrm{L}$ saturated sodium carbonate $(10 \%, \mathrm{w} / \mathrm{v}$ aqueous solution). After $2 \mathrm{~min}$ of incubation at room temperature $\left(20 \pm 5{ }^{\circ} \mathrm{C}\right)$, the mixture was placed in the dark for $1 \mathrm{~h}$. Absorbance was then measured at $750 \mathrm{~nm}$. Gallic acid was used to obtain the calibration curve (10 to $100 \mu \mathrm{g} / \mathrm{mL}$ ), and the concentration of TPC was expressed as gallic acid equivalent (GAE)/g of dry extract.

TFC was measured spectrophotometrically using the $\mathrm{AlCl}_{3}$ method [48]. Briefly, each extract $(0.5 \mathrm{~mL})$ of $10 \mathrm{mg} / \mathrm{mL}$ was mixed with $1.0 \mathrm{~mL}$ of $2 \%(\mathrm{v} / \mathrm{v}) \mathrm{AlCl}_{3} \cdot 6 \mathrm{H}_{2} 0$ absolute ethanolic solution and the absorbance was measured after $10 \mathrm{~min}$ at $430 \mathrm{~nm}$. Quercetin was used to obtain the calibration curve $(0.01-50 \mu \mathrm{g} / \mathrm{mL})$, and the concentration of TFC was expressed as quercetin equivalent (QE)/g of dry extract.

Similarly, TCT was determined using a previously developed method by Julkunen-tiitto [27] and Slinkard and Singletod [47] using catechin as a reference compound to obtain a standard curve (50-1000 $\mu \mathrm{g} / \mathrm{mL})$. Briefly, an aliquot of each extract $(50 \mu \mathrm{L})$ was mixed with $1.5 \mathrm{~mL}$ of $4 \%(\mathrm{w} / \mathrm{v})$ vanillin in absolute ethanol, followed by the addition of $750 \mu \mathrm{L}$ concentrated $\mathrm{HCl}$. The mixture was allowed to stand at room temperature for $20 \mathrm{~min}$ in the dark. The blank was $4 \%(\mathrm{v} / \mathrm{v})$ concentrated $\mathrm{HCl}$ in absolute ethanol. The absorbance was read at $500 \mathrm{~nm}$ against a blank. Results were expressed in catechin equivalent $(\mathrm{CE}) / \mathrm{g}$ of dry extract which reflects the tannin content.

The sustainability of antioxidative activities of same consequential microencapsulated powders were appraised in terms of total antioxidant activity evaluated by $\beta$-carotene bleaching assay (TOAA), cupric ion reducing antioxidant capacity (CUPRAC), and chelating effects on ferrous ions assays (CHELAT). All these spectrophotometrically analysis were accomplished conferring to our formerly developed procedures for MC [22, 23]. The chelating activity was articulated as $\mathrm{EC}_{50}$, the concentration (in $\mathrm{mg} / \mathrm{mL}$ ) that chelated $50 \%$ of the $\mathrm{Fe}^{2+}$ ions. So the outcomes of CHELAT were standardized and articulated as $\mathrm{EC}_{50}$ values (mg extract per $\mathrm{mL}$ ) for appraisal. Effectiveness of antioxidant properties is inversely correlated with $\mathrm{EC}_{50}$ value.

\section{Release kinetics of microencapsulated powder} during simulated in vitro enzymatic digestion

Simulated enzymatic digestion was carried out in line with the previously reported literature procedure with slight modifications [38]. Since ethanolic extracts of MCWJ11 were found to be rich in phenolic compounds $[22,23]$ so the release kinetics of phenolic compounds was also focused in this in vitro digestion model. Gastrointestinal (GI) digestion is of two phases: gastric and intestinal digestion. Pure ethanolic extracts and mixed microcapsule-mycelial solution (henceforth referred and denoted as matrix solution) were examined as standard samples. The incubation of samples was done in (simulated)gastric fluid condition devoiding enzyme (SGDig, $\mathrm{pH}$ 1.2) and fed-state condition having simulated intestinal fluid containing pancreatin (FSIDig, $\mathrm{pH}$ 6.8) at $37 \pm 1{ }^{\circ} \mathrm{C}$. To ensure the effective diffusive release of phenolics in the aqueous medium and for the appraisal of acidic pH impact on stability of TPCs, as compared to stability of TPCs in FSIDig, pepsin was not added in SGDig.

\section{Release media}

The gastric conditions were created devoiding any enzyme denoted as SGDig pH 1.2 (USP 32) while (small) intestinal condition (FSIDig) was phosphate buffer $\mathrm{pH}$ 6.8 (46.6\% disodium hydrogen phosphate dihydrate $1 / 15 \mathrm{M}, 53.4 \%$ potassium dihydrogen phosphate $1 / 15 \mathrm{M}$ ) accompanied with $15 \mathrm{mM}$ bile salts, $3.75 \mathrm{mM}$ phospholipids, $150 \mathrm{mM}$ sodium chloride, $450 \mathrm{U} / \mathrm{mL}$ pancreatin as enzyme source, and $5 \mathrm{mM}$ calcium chloride [38]. The bile acid content of the heterogenic porcine bile extract used was assayed using the enzymatic Ecoline S+ test (Diagnostic Systems, Holzheim, Germany) and adjusted as appropriate prior to its addition.

\section{In-vitro release systems}

In vitro release kinetics of microcapsule powder and degradation kinetics of nonencapsulated polyphenol rich ethanol extracts were monitored during continuously agitated $(10 \mathrm{rpm})$ and incubated vessel, agitated about parallel hatchets, in an end-over-end agitator furnished with a control system of temperature. Prior to start the experiment release media and capsule powder were warmed to $37 \pm 1{ }^{\circ} \mathrm{C}$, and the whole system was maintained at that temperature in course of each incubation. Samples of both microbial ethanolic extracts (nonencapsulated and undigested) and microcapsule-loaded extracts (undigested) were impregnated (at rate so that initial TPCs/polyphenolics concentration was set to $0.7 \%)$ to the incubation media. This concentration was recognized to be referenced as $100 \%$ (around $6000 \mathrm{GAE}$ )/ $\mathrm{kg}$ of dry extract), and all successive concentrations of 
succeeding samples were taken in relation to this value. Ensuing standard pharmacopoeia approach (Ph. Eur. 6.8, USP 32), incubation of the compounds were lasted for 120 min in SGDig. Following a deviation to a higher $\mathrm{pH}$ in medium, the most of global pharmacopoeias endorse a 45 min increase in the incubation to thoroughly evaluate the discharge of tested compounds. So consequently, both the non-capsular and capsular powder were encapsulated for $120 \mathrm{~min}$ in the FSIDig medium as bioactive compounds sustained to be discharged from the investigated capsule systems after incubation time of $45 \mathrm{~min}$ in it. At pre-determined time intervals (0 to $120 \mathrm{~min}$ SGDig and 0 to $150 \mathrm{~min}$ for those in FSIDig), the $\mathrm{pH}$ was sustained to 6.8 (initial value) for samples incubated in the FSIDig, whereas as for samples in the SGDig the $\mathrm{pH}$ did not fluctuate significantly, so no such $\mathrm{pH}$ adjustment was required. For analytical evaluations, an aliquot of $100 \mu \mathrm{L}$ samples were taken with subsequent dilution with mixture $(900 \mu \mathrm{L})$ of methanol/formic acid/bidistilled water $(50 / 10 / 40, \mathrm{v} / \mathrm{v} / \mathrm{v})[38]$ to terminate any possible enzyme reaction and for stabilization of the polyphenols. Successively, the mixture containing polyphenols was undergone centrifugation (10,000 rpm for $5 \mathrm{~min}$ ) (Centrifuge 5810/5810R, Eppendorf AG, Hamburg, Germany) to get the separated dispersed components. After centrifugation, supernatants from the mini Eppendorf centrifugation tubes were transferred to amber colored glass vials and kept at $-20{ }^{\circ} \mathrm{C}$ until analysis.

\section{Acute toxicity}

The acute oral toxicity study was carried out in compliance with Organization for Economic Cooperation and Development (OECD) guideline 425 [37]. The male albino mice $(\mathrm{n}=21)$, divided into two groups i.e. control $(10 \times 1=10)$ and treated $(11 \times 1=11)$ intended for underway investigations were fasted $12 \mathrm{~h}$ prior consumption of dosage. During this period, weights of all mice were noticed and afterwards only treated group was given the dose in form of solution of microencapsulated products of microbial extracts $(2000 \mathrm{mg} / \mathrm{kg})$ by gavage. The control group was given the saline solution without the microbial extracts. After dosing, the mice were observed individually critically for first $30 \mathrm{~min}$, intermittently for the first day $(24 \mathrm{~h})$, and recurrently subsequently for fortnight of feeding period for any possible toxicity symptoms, toxicity, gross behavioral changes, and/or mortality.

\section{Preparation of cottage cheese with incorporation of microbial extracts and its nutritional and sensory evaluation}

The cottage cheese was prepared and supplied on special request by the local cheese manufacturing company according to our prescribed instructions/recipes and without the addition of any additive and/or colorant and/ or flavoring agent. Three groups of cottage cheese (each comprising $100 \mathrm{~g}$ ) were designed in such way that (i) a group without the addition of any extract was taken as control (ii) cheese with the addition of best performing microencapsulated powder i.e. 5\% WPHG $+5 \%$ pectin $\left(\mathrm{T}_{\mathrm{A}}\right)(3 \mathrm{~g} / 100 \mathrm{~g}$ cheese) and (iii) cottage cheese with microbial ethanolic free extracts $(80 \mathrm{mg} / \mathrm{mL})$.

The nutritional and sensory evaluation of the samples (control sample, cottage cheeses added with microencapsulated powder extracts and cottage cheeses added with microbial ethanolic free extracts) was performed right after the preparation $\left(\mathrm{T}_{\mathrm{o}}\right)$ and after 7 days of storage $\left(\mathrm{T}_{7}\right)$ at $4{ }^{\circ} \mathrm{C}$. The nutritional composition (ash, moisture, protein, fat, and carbohydrate) was calculated according to AOAC procedures [5]. The antioxidant capacity of samples was determined according to the DPPH assay described by Hameed et al. [22, 23]. Briefly, freshly prepared $0.3 \mathrm{mM}$ solution of DPPH was mixed with $2.5 \mathrm{~mL}$ $5 \mathrm{mg} / \mathrm{mL}$ sample extracts and reaction mixture was kept in the dark for $20 \mathrm{~min}$ in glass tubes. The decreasing absorbance was measured at $517 \mathrm{~nm}$ to calculate the percentage inhibition of the radicals. Whereas the reducing power of the samples were measured according to above described CUPRAC assay. The sum of saturated fatty acids (SFAs), mono-unsaturated fatty acids (MUSFAs) and polyunsaturated fatty acids (PUFAs) were determined by summing up their respective kind of fatty acids detected via by analyzing the petroleum ether extract previously obtained, by gas-chromatography coupled with a flame ionization detector (GC-FID), according to the procedure described by Reis et al. [44]. Sample color was measured in a colorimeter (model CR-400, Konica Minolta Sensing, Inc., Japan), using the illuminant C and a diaphragm aperture of $8 \mathrm{~mm}$. The CIE Lab/ colour space values were recorded using the data software "Spectra Magic Nx" (version CM-S100W 2.03.0006). Three readings on the sample top and bottom parts, were used.

\section{Cheese liking evaluation}

In order to check whether the addition of free or microencapsulated extracts had any influence on the sensory scores of cheeses, a study was carried out comprising one hundred fourteen consumers (63 females and 51 males aged from 16 to 55 years old). They were conscripted rendering to their inclination to join in, and with the obligation of consuming cheese (at least one time a day) and not owing any kind of intolerance to cheese or cheese components. Three cottage cheese (each $100 \mathrm{~g}$ ) were served to consumers: ' $C$ ' (control cottage cheese without additions of any extract), CapC (cottage cheese with added microcapsule powder), and 'FExC' (cottage cheese 
added free extracts) without sharing any information about the contents of cheese. Consumers were instructed to write down their consuming experience of cottage cheese in relation to texture, global, and taste fondness by nine-point hedonic scales ranging from $1=$ "dislike extremely" to $9=$ "like extremely". For identification, the samples were coded with three-digit roman numbers codes and were served with a balanced design [33]. Between samples, consumers were given mineral water to rinse their mouth to further avoid any wrong sensory perception by consumers. All experiments were accomplished in submission with the local/national legislation, and according to the institutional framework and practices established University Ethics Committee. A written consent was received from each participant after the disposal of written information before the induction of each sensory evaluation activity.

\section{Statistical analysis}

All the experimental data has been repeated three times. All statistical analyses were conducted using a two-way analysis of variance with Dunnett's comparison tests or unpaired t-tests. These calculations were carried out using GraphPad Prism Software for Windows (GraphPad Software, San Diego, CA, USA). Significance was observed at $\mathrm{p}<0.05$.

\section{Results and discussion}

\section{Physico-chemical properties of microencapsulated powders}

The physico-chemical characterization is important crucial to understand the physico-chemical interaction that occurred between the extracts and the wall material which would help us to estimate the preservation of antioxidant capacity of microcapsules in food products [51]. The knowledge of hygroscopicity and solubility is essential to know about the powder stability and storage, reconstitution and, hence, bio-digestibility/bioaccessibility respectively. The physico-chemical properties of four kinds of microcapsule $\left(T_{A}, T_{B}, T_{C}\right.$, and $\left.T_{D}\right)$ powders are shown in the Fig. 1. As can be seen in Fig. 1, the nature of wall material has significance influence on the physico-chemical properties and morphology of the resulting powders. Generally, microcapsules showed significantly higher $(\mathrm{p}<0.0001)$ moisture contents and water activity $\left(\mathrm{A}_{\mathrm{w}}\right)$ values than the control. Additionally, among the four treatments, all the microencapsulated powders exhibited considerable difference for moisture and $A_{w}$ with the 5\% WPHG $+5 \%$ pectin $\left(\mathrm{T}_{\mathrm{A}}\right)$ and $5 \%$ PHGG and $5 \%$ pectin $\left(\mathrm{T}_{\mathrm{C}}\right)$ showed highest moisture $(7.5 \pm 0.1 \%$ and $6.2 \pm 0.1 \%$ respectively) whilst at the same time $\mathrm{T}_{\mathrm{A}}$ and $10 \%$ of PHGG $\left(\mathrm{T}_{\mathrm{D}}\right)$ showed highest $\mathrm{A}_{\mathrm{w}}(0.26 \pm 0.01$ and $0.27 \pm 0.01$ respectively) (Fig. 1a, b). The moisture and
$\mathrm{A}_{\mathrm{w}}$ range detected for all treatment was 5.5 to $7.5 \%$ and 0.14 to 0.27 respectively. All the encapsulated powders showed moisture contents and $\mathrm{A}_{\mathrm{w}}$ below the threshold levels specified for microencapsulation by freeze drying [49]. So, the possible reason of higher moisture and $A_{w}$ of microcapsule powders goes to adopted encapsulation methodology (i.e. freeze drying) for which many authors have also confirmed higher moisture contents and $A_{w}$ compared to other methods of microencapsulation [16, 31]. The smaller pore size in the surface of wall material also hampers the mass transfer of moisture during sublimation at freezing temperature (i.e. -40 or $-60{ }^{\circ} \mathrm{C}$ ) which probably resulted in increase in water retention. The observed solubility of microcapsule powders varied from $70.44 \pm 1.4 \%\left(\mathrm{~T}_{\mathrm{D}}\right)$ to $93.4 \pm 1.01 \%\left(\mathrm{~T}_{\mathrm{A}}\right)$. The combination of $5 \%$ WPHG $+5 \%$ pectin $\left(\mathrm{T}_{\mathrm{A}}\right)$ showed highest solubility values after control (Fig. 1c). The huge variation in the solubility trend of all microcapsule powders clearly bespeaks about the dependence of this parameter on the nature of wall material which means that microcapsule powders with high solubility index can be easily and effectively reconstituted in the water system for their application in food and pharmaceutical processing. Regarding hygroscopicity, a range of $4.9 \pm 0.01\left(\mathrm{~T}_{\mathrm{B}}\right)$ to $12.4 \pm 1.07\left(\mathrm{~T}_{\mathrm{C}}\right)$ was noticed (Fig. 1d), describing a low value for all encapsulated powders especially for $T_{B}$ and TA. The low value of hygroscopicity is beneficial for the conservation and preservation of the bioactive components MC extracts. Despite the higher moisture contents, the lower hygroscopic values was also associated with the freeze drying method as larger particle size is found in microencapsulation by freeze drying compared to spray dried product [34]. Glass transition temperature $\left(\mathrm{T}_{\mathrm{g}}\right)$ values are in a close relationship with stability of microcapsules while storage. Greater $\mathrm{T}_{\mathrm{g}}$ values usually refers to greater stability of powders. The $\mathrm{T}_{\mathrm{g}}$ of all powders were found in the range of $14.1 \pm 0.3\left(\mathrm{~T}_{\mathrm{D}}\right)$ to $55.4 \pm 1.2\left(\mathrm{~T}_{\mathrm{A}}\right)$ (Fig. 1e). The variation in the $T_{g}$ of all treatments may be attributed to vast variations in the molecular weight and moisture contents of resulting powders as wall materials with higher molecular weights showed higher $\mathrm{T}_{\mathrm{g}}$ previously [31]. Consequently, the treatments with combination of two wall materials $\left(\mathrm{T}_{\mathrm{A}}\right.$ and $\left.\mathrm{T}_{\mathrm{C}}\right)$ showed higher $\mathrm{T}_{\mathrm{g}}$ than that of others (Fig. 1e).

\section{Morphology and size distribution}

In order to fully establish and apprehend the competencies of microcapsules with respect to their potential applications, it is also necessary to characterize the microcapsules with reference to their morphology and size distribution. The size of microcapsules is crucial in relation to their flowing and mechanical properties, shipment and adhesion to the surface. The microcapsules 

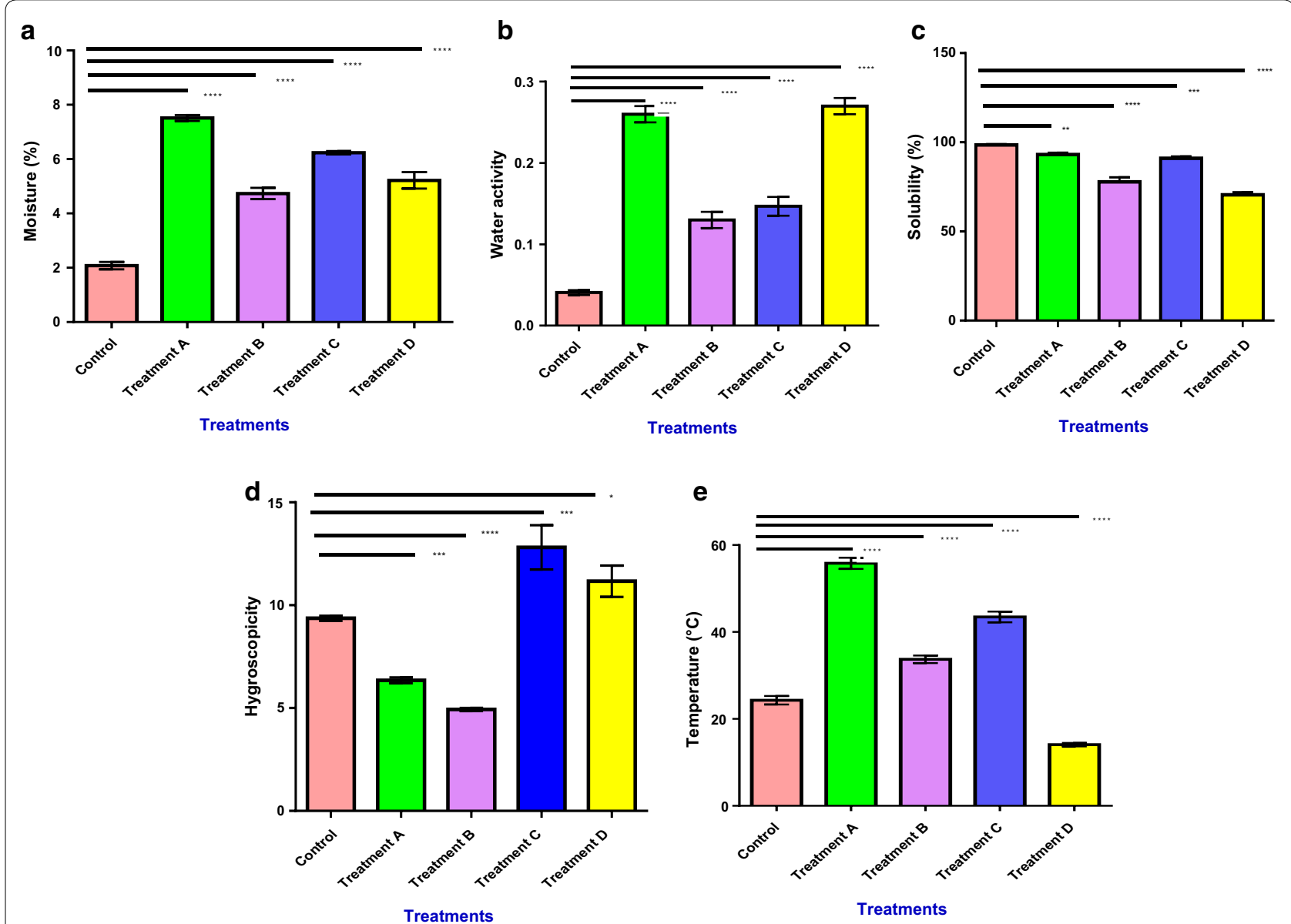

Fig. 1 Physico-chemical properties of microbial ethanolic extracts microencapsulated with Treatment $A\left(T_{A}\right)$, Treatment $B\left(T_{B}\right)$, Treatment $C\left(T_{C}\right)$, and Treatment $D\left(T_{D}\right)$ by freeze drying. Data is represented as mean of $3 n \pm S . D$. ${ }^{* * *}$ Very extremely significant $(p$-value $<0.00001)$, ${ }^{* * *}$ extremely significant $(0.00001<p$-value $<0.0001)$, ${ }^{* *}$ very significant $(0.0001<p$-value $<0.001)$, significant $(0.001<p$-value $<0.01)$, and ns not significant

from each treatment showed varied surface morphology, size, and very dissimilar topography. Figure 2 showed the micrograph of microcapsule powders from each treatment. All the microcapsules exhibited non-ellipsoidal, slightly toothed morphology with rough surface devoiding any fissures, cracks or pores except $T_{D}$ which showed deep depressions or/and pores in the surface. The nonexistence of pores, as in first three treatments, is crucial for maintaining the stability and integrity of microcapsules, and an indicator for the high efficiency of microencapsulation process which ultimately warranty the safe and targeted delivery of bioactive compounds too. Whereas, the presence of pores usually permits the entry of oxygen and in turn facilitates the oxidation of bioactive compounds. Moreover, Table 1 represents the particle size distribution and average particle size of the four treatments. The diameter of freeze-dried microcapsules ranged from 12.06 to $42.75 \mu \mathrm{m}$. The observed diameter range was found less than the previous finding of other authors which may be due to manual excessive size reduction via mortar and pestle [11, 18, 51]. Additionally, the other possible reason of smaller diameter is the lack of agglomeration since the formation of irreversible bridges may lead to formation of larger particles [51]. This evidence of non-agglomeration is also guarantee longer shelf life of microcapsules even under accelerated storage conditions. With respect to span values, the observed span scores were ranged from $1.72\left(\mathrm{~T}_{\mathrm{D}}\right)$ to 2.28 $\left(\mathrm{T}_{\mathrm{A}}\right)$. All treatments showed the span values lower than observed span values by previous authors for microencapsulation of plant extracts $[18,19]$. These lower span values for microencapsulation of microbial antioxidants also symbolic to more homogenous particle distribution in the microcapsule powders of four treatments.

\section{Flow properties of microencapsulated powders}

All the microencapsulated powders showed regular powder flowing properties with non-significant $(\mathrm{p}>0.05)$ 


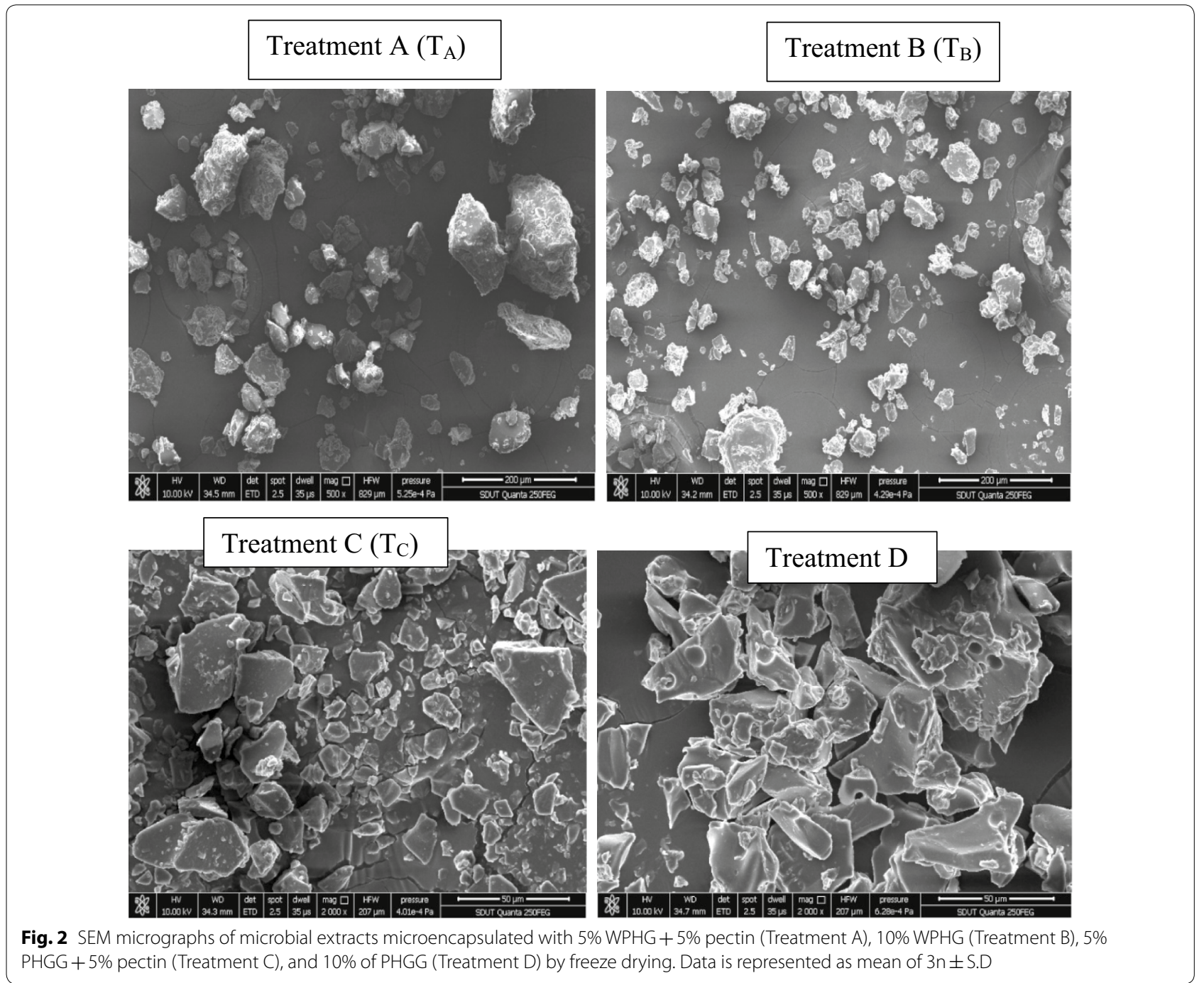

Table 1 Average diameter and particle size distribution (Span) of the microbial extract microencapsulated with WPHG, pectin and PHGG and their combinations by freeze-drying method

\begin{tabular}{lll}
\hline Treatments & Average diameter $(\boldsymbol{\mu m})$ & Span \\
\hline $\mathrm{T}_{\mathrm{A}}$ & $12.06 \pm 1.3$ & $2.28 \pm 0.2$ \\
$\mathrm{~T}_{B}$ & $42.75 \pm 3.7$ & $1.97 \pm 0.07$ \\
$\mathrm{~T}_{C}$ & $21.80 \pm 2.2$ & $2.49 \pm 0.1$ \\
$\mathrm{~T}_{\mathrm{D}}$ & $25.36 \pm 1.6$ & $1.72 \pm 0.3$ \\
\hline
\end{tabular}

Data is represented as mean of $3 n \pm S . D$

variations among all the microencapsulated wall material treatments (Table 2). $\mathrm{T}_{\mathrm{A}}$ and $\mathrm{T}_{\mathrm{B}}$ showed highest bulk and particle density values which are highly desirable for safe product processing, transport and packaging activities the powders with high bulk density also offer less empty intra-particle available spaces for air or/and oxygen which means less probability of product degradation via oxidation [49]. The particle density of all microcapsules varied from 750 to $730 \mathrm{~kg} / \mathrm{m}^{3}$ which is an indication of identical porosity index in all microcapsule powders and existence of rough or/and toothed surfaced microcapsules [49]. The angle of repose of all powders was about $40-42^{\circ}$ and similarly the percentage compressibility of all microcapsules was near $40 \%$ (Table 2). An angle of repose within the range of $40-45^{\circ}$ was a good symbol of powders with desired flow characteristics and low Hausner ratio $(0.9-1.1)$ were symbolic to powder viscosity having cohesiveness, an expressive of negligible poor flow with possible cohesive forces [6]. Regular surface morphology and large particles from freeze dried powders may be attributed towards the reduced Hausner ratio which resulted in improved flow properties with decreased cohesive forces [40]. The higher microencapsulation yield 
Table 2 Flow properties of microbial extracts microencapsulated with $5 \%$ WPHG $+5 \%$ pectin $\left(T_{A}\right), 10 \%$ WPHG $\left(T_{B}\right), 5 \%$ PHGG $+5 \%$ pectin $\left(T_{C}\right), 10 \%$ of PHGG $\left(T_{D}\right)$ by freeze drying

\begin{tabular}{|c|c|c|c|c|}
\hline Parameters & $\begin{array}{l}5 \% \text { WPHG }+5 \% \text { pectin } \\
\left(T_{A}\right)\end{array}$ & $10 \%$ WPHG $\left(T_{B}\right)$ & $\begin{array}{l}5 \% \text { PHGG }+5 \% \text { pectin } \\
\left(\mathrm{T}_{\mathrm{C}}\right)\end{array}$ & $10 \%$ of PHGG $\left(T_{D}\right)$ \\
\hline Bulk density $\left(\mathrm{kg} / \mathrm{m}^{3}\right)$ & $137.5 \pm 3.9 a$ & $135.2 \pm 4 a$ & $132.8 \pm 5.9 \mathrm{a}$ & $132.2 \pm 3.1 \mathrm{a}$ \\
\hline Compact density $\left(\mathrm{kg} / \mathrm{m}^{3}\right)$ & $224.8 \pm 3.1 \mathrm{a}$ & $221.3 \pm 3.4 a$ & $220.5 \pm 5.3 a$ & $219.6 \pm 4.9 a$ \\
\hline Particle density $\left(\mathrm{kg} / \mathrm{m}^{3}\right)$ & $747.5 \pm 3.9 a$ & $740.7 \pm 2.5 a$ & $739.3 \pm 5.6 a$ & $737.6 \pm 6.0 \mathrm{a}$ \\
\hline Angle of repose $\left(^{\circ}\right)$ & $42.6 \pm 1.8 \mathrm{a}$ & $41.6 \pm 0.7 a$ & $43.3 \pm 1.6 a$ & $42.2 \pm 1.1 \mathrm{a}$ \\
\hline Chroma & $23.3 \pm 1.1 \mathrm{a}$ & $24.3 \pm 0.7 a$ & $25.7 \pm 0.5 a$ & $23.1 \pm 0.9 a$ \\
\hline Compressibility (\%) & $42.2 \pm 2.5 \mathrm{a}$ & $40.5 \pm 1.3 \mathrm{a}$ & $41.2 \pm 0.5 a$ & $39.5 \pm 1.1 \mathrm{a}$ \\
\hline Hausner ratio & $0.93 \pm 0.1 \mathrm{a}$ & $1.1 \pm 0.3 \mathrm{a}$ & $0.97 \pm 0.1 \mathrm{a}$ & $1.13 \pm 0.0 \mathrm{a}$ \\
\hline Yield microencapsulation (\%) & $95.3 \pm 1.7 a$ & $93 \pm 1.2 \mathrm{a}$ & $93.9 \pm 2.2 \mathrm{a}$ & $91.1 \pm 1.1 \mathrm{a}$ \\
\hline
\end{tabular}

Data are expressed as $3 n \pm$ S.D. Same letters within the same row mean a non-significant difference $(p>0.05)$

$(>90 \%)$ in all freeze-dried powders, especially with $5 \%$ WPHG $+5 \%$ pectin $\left(\mathrm{T}_{\mathrm{A}}\right)$, showed excellent retention of microbial extracts during microencapsulation by freeze drying (Table 2). It is established fact that wall materials of WPHG or with combination of starchy/sugary material form a crust having reduced inner impact with limited convection heat transfer phenomenon, and consequently, minimum loss of extracts via volatilization or surface diffusion during subsequent operations. Some studies also suggested that there is no observed interaction between the protein hydrogels, used as wall material, and the polyphenol extracts so that kind of wall material could function as safe container with higher retain-ability and guaranteed protection [46].

\section{Antioxidant components and antioxidative activities}

The antioxidant components and bioactivities of freshly extracted pure ethanolic extract (control) and their lyophilized microencapsulated powders from four treatments $\left(\mathrm{T}_{\mathrm{A}}, \mathrm{T}_{\mathrm{B}}, \mathrm{T}_{\mathrm{C}}\right.$, and $\left.\mathrm{T}_{\mathrm{D}}\right)$ are shown in Fig. 3. With respect to TPC, all the microencapsulation treatments showed significantly less $(\mathrm{p}<0.0001)$ TPC compared to control except $\mathrm{T}_{\mathrm{A}}$ whose TPC were found to be nonsubstantially different from the control (Fig. 2a). Among the treatments, only $\mathrm{T}_{\mathrm{A}}$ was found to retain significantly higher contents $(\mathrm{p}<0.05)$ of phenolic compared to $T_{B}$, $T_{C}$, and $T_{D}$ whereas non-significance retain-ability of TPC was detected while making comparison among $\mathrm{T}_{\mathrm{B}}, \mathrm{T}_{\mathrm{C}}$, and $\mathrm{T}_{\mathrm{D}}$. Almost same trend was detected, while measuring the TFC and TCT of control and four treatments as observed in TPC calculations, except in TCT where TCT of $\mathrm{T}_{\mathrm{A}}$ was weakly but significantly lower than that of control (Fig. 3c). The bioactivities of control (pure ethanolic extract) and four treatments showed a bit different tendency than the bioactive components. The bioactivities of all microencapsulated powders were significantly $(\mathrm{p}<0.0001)$ lower than that of control. The main reason of low bioactivities of all microencapsulated powders might be due to loss and degradation of polyphenolic compounds during microencapsulation and re-extraction of polyphenolic extracts from powders. In $\beta$-carotene bleaching and CUPRAC assays, not only all the walled material powders showed less bioactivity than that of control but substantial variations also existed among all the four treatments, however, in chelating assay, a non-significant variation was noticed between control and TA. According to results, 5\% WPHG +5\% pectin $\left(\mathrm{T}_{\mathrm{A}}\right)$ showed the maximum retain-ability $(>80 \%)$ of the microbial antioxidant components and their bioactivities followed by $\mathrm{T}_{\mathrm{C}}$ (5\% PHGG and 5\% pectin). So, microencapsulation of microbial bioactive extracts with $5 \%$ WPHG $+5 \%$ pectin can be a viable option for protecting microbial bioactive components of $\mathrm{MC}$ against degradation during the processing and storage.

\section{In-vitro digestion, targeted and control release,} and bio-accessibility studies of microencapsulated powder Polyphenols mostly exist in their stable cationic form after gastric digestion, and converted and degraded to their aldehyde, acidic, or ketonic (i.e. ketonic hemiketal, quinonoidal, and chalcone) forms in intestinal phase to higher $\mathrm{pH}$ [13]. This transformation and annihilation of polyphenols at intestinal level is one of the main reasons of their low bioavailability at intestinal phase. Therefore, it was of highly desirable and likely to check either microencapsulation of $\mathrm{pH}$ sensitive microbial antioxidants with the best-found whey protein isolate hydrogel + pectin combination $\left(\mathrm{T}_{\mathrm{A}}\right)$, was a good strategy in delivering the $\mathrm{pH}$ thermo-labile microbial bioactive compounds in their most active form (cationic) at intestinal phase. For this purpose, microbial polyphenols released from microcapsules $\left(\mathrm{T}_{\mathrm{A}}\right)$ were measured from simulated intestinal fluid, in order to establish the fact that whey protein hydrogel + pectin $\left(\mathrm{T}_{\mathrm{A}}\right)$ can be considered an appropriate 
a

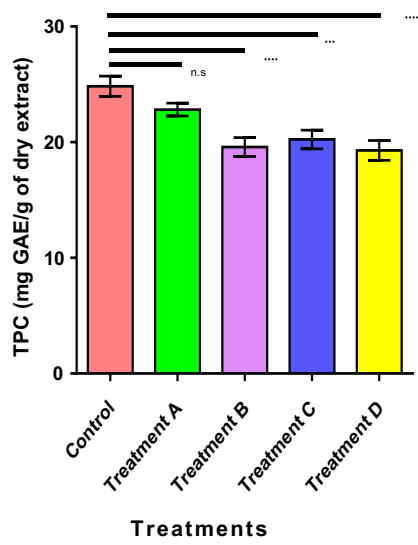

d

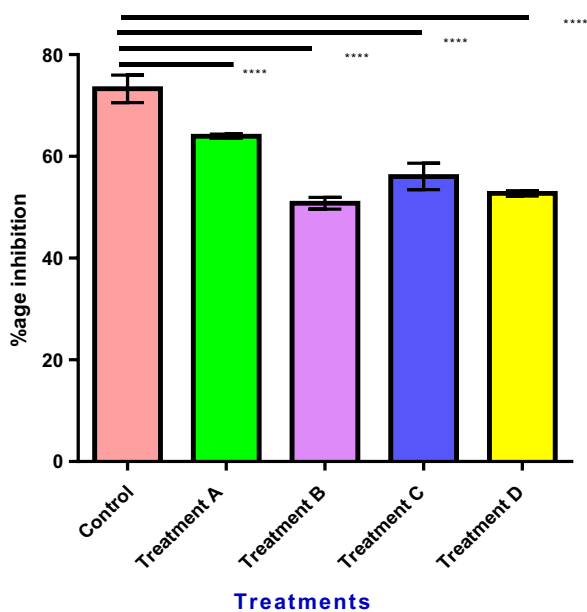

b

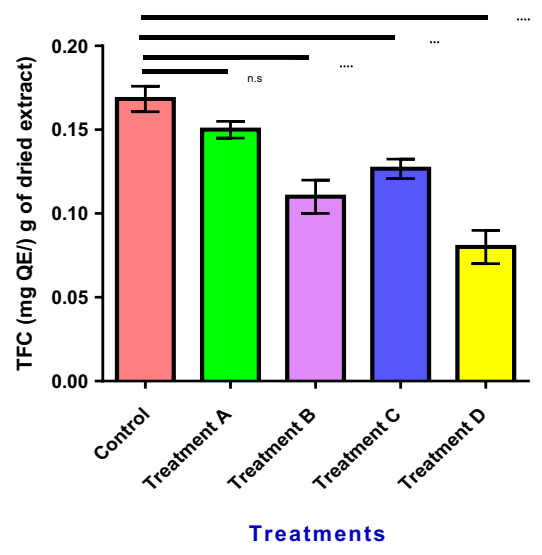

e

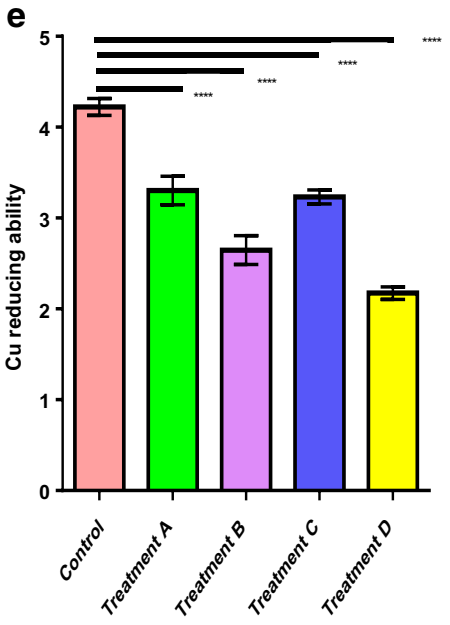

Treatments

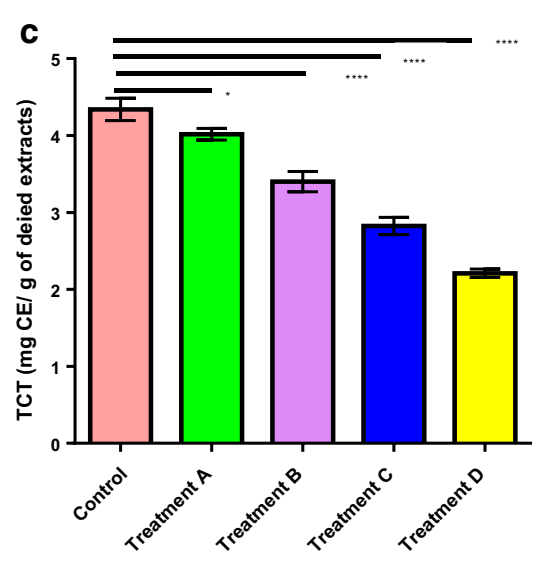

Treatments

f

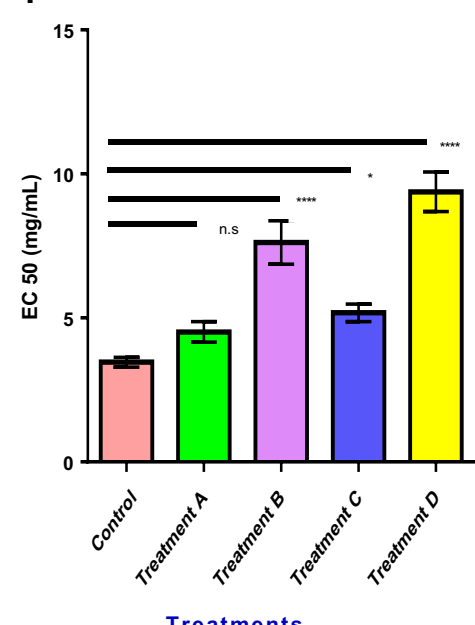

Fig. 3 Antioxidant components and antioxidant activity of free ethanolic extracts (control) and microcapsules powders encapsulated with Treatment $A\left(T_{A}\right)$, Treatment $B\left(T_{B}\right)$, Treatment $C\left(T_{C}\right)$, and Treatment $D\left(T_{D}\right)$ by freeze drying. Results expressed as $3 n \pm S . D$. TPC based on calibration curve of gallic acid, expressed as mg gallic acid equivalents (GAE) per gram of dry extract; $r=0.993$. TFC expressed as mg quercetin equivalents (QE) per gram of dry extract; $r=0.9891$. TCT content based on calibration curve of $(+)$-catechin, expressed as mg catechin equivalents (CE) per gram of dry extract; $r=0.991$. The values $\beta$-carotene bleaching assay of selected extracts $(\mathrm{mg} / \mathrm{mL})$ based on percent bleaching inhibition. CUPRAC of selected fungal extracts $(\mathrm{mg} / \mathrm{mL})$ based on absorbance $(\lambda 450 \mathrm{~nm})$. EC 50 values $(\mathrm{mg} / \mathrm{mL})$ is representative of the effective concentration at which $50 \%$ of $\mathrm{Fe}^{2+} / \mathrm{Cu}^{2+}$ ions were chelated. ${ }^{* * * *}$ Very extremely significant ( $p$-value $\left.<0.00001\right)$, ${ }^{* *}$ extremely significant $(0.00001<p$-value $<0.0001)$, ${ }^{* *}$ very significant $(0.0001<p$-value $<0.001)$, significant $(0.001<p$-value $<0.01)$, and ns not significant

matrix for stabilizing polyphenols at severe intestinal conditions. Pure and freshly extracted ethanolic extracts and non-gelled mixed whey protein-microbial extract solution (matrix solution) were incubated as reference samples (Fig. 4). The pure and freshly extracted ethanolic extracts were also impregnated with the microcapsule powders to calculate the relative polyphenolic concentration. This relative polyphenolic concentration was maximum $(\sim 6000 \%)$ at $\mathrm{t}=0$ and taken as refence for the subsequent measurements of stability and release kinetics of microencapsulated and non-microencapsulated extracts in digestion media. At gastric phase, most of polyphenols found to exist in their stable cationic form [13], thus after incubation of freshly extracted mycelial ethanolic extracts of $\mathrm{MC}$ at $\mathrm{pH} 1-2$, negligible annihilation of polyphenols happened and polyphenolic concentration stayed constant at $75-85 \%$ of total phenolic contents (Fig. 4). Moreover, the relative polyphenolic concentration of microencapsulated powders and gelled matrix released polyphenolic extracts doubled within the initial $30 \mathrm{~min}$ of incubation. This considerable increased in the relative polyphenolic concentration might be dedicated to time-dependent protection of wall material and subsequent release of polyphenolic rich extracts with 

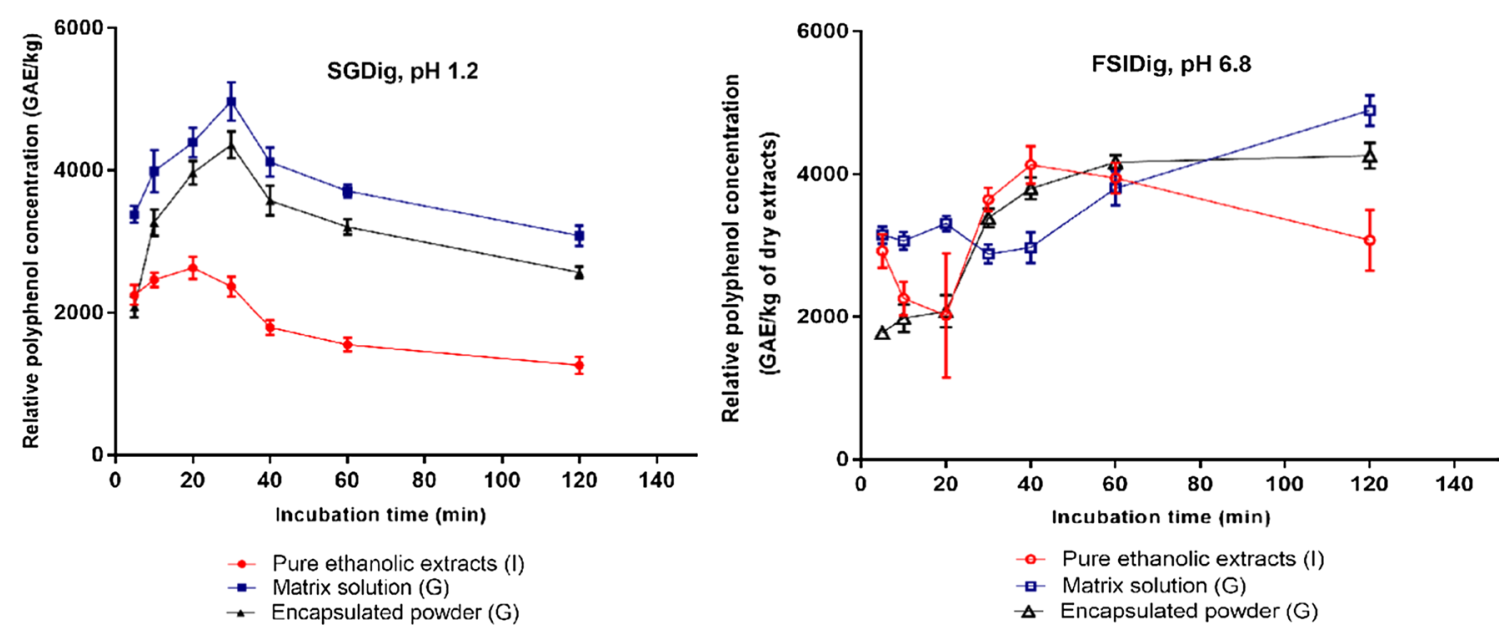

Fig. 4 Time-dependent relative polyphenol concentration in simulated gastric fluid without enzyme (SGDig, pH 1.2) (closed symbols) and fed-state simulated intestinal fluid with pancreatin (FSIDig, pH 6.8) at $37 \pm 1{ }^{\circ} \mathrm{C}$ (open symbols) after incubation of the free ethanolic microbial extract (circles) the mixed non-gelled whey protein-microbial ethanolic extract solution (matrix solution) (cubes) and the corresponding microbial ethanolic extract-loaded microcapsules (triangles). The maximum TPC was noted from the initial $0.7 \%$ polyphenols concentration (set as reference) in release media of all samples which was around $6000 \mathrm{GAE}$ )/kg of dry extract. This TPC value was set as maximum measured TPC at incubation $\mathrm{t}=0$ and all the latterly measured polyphenolic concentration (from incubation $t=0$ to $t=120 \mathrm{~min}$ ) were described as relative polyphenolic concentration to this maximum limit. The incubation in SGDig and FSIDig was carried out independently, not consecutively. Data are given as $3 n \pm$ confidence interval at $95 \%$

minimal exposure to digestion media. However, it was not the same case with non-encapsulated pure extracts due to which its relative polyphenolic concentration dropped enormously.

In intestinal phase, the severe $\mathrm{pH}$ condition (6.8) lead to degradation of almost $30 \%$ of ethanolic polyphenolic extracts during the very first 5 min of incubation especially in case of pure ethanolic extracts. So, a trend of continuous and sudden degradation of remaining polyphenols from intentionally added ethanolic extracts was noticed. After $120 \mathrm{~min}$ of incubation, only $30 \%$ of initially added polyphenolic contents of ethanolic extracts were left. There was seen an increase in the relative polyphenolic concentration from 20 to $90 \mathrm{~min}$ both in microencapsulated and intentionally added pure ethanolic extracts. However, this increased in relative polyphenolic concentration was more in pure ethanolic extracts but could not sustain after 90 min of incubation while microencapsulated extracts showed a sustainable and continually increasing relative polyphenolic concentration after $20 \mathrm{~min}$ which surpassed the relative polyphenolic concentration of pure ethanolic extracts after $90 \mathrm{~min}$ (Fig. 4). The increase in the relative polyphenolic concentration of pure ethanolic might be due to degradation of polyphenolic compounds into secondary polyphenolic compounds which might act as pro-antioxidants. The sustainable and continually increasing relative polyphenolic concentration of microcapsules might envisage the important role of microencapsulation of extracts in timely and targeted delivery of core extracts. Of note, the relative polyphenolic concentration of matrix solution (reference) was of highest from $40 \mathrm{~min}$ to onward as compared to relative polyphenolic concentration of pure ethanolic extracts and microcapsules which might be due to better provision of shield by non-gelled matrix to extracts. In addition, the degradation rate of polyphenols was less than the release rate of polyphenols from microcapsules during the first $40 \mathrm{~min}$ of incubation in intestinal $\mathrm{pH}$. As a result, a substantially higher amount of polyphenolic compounds could be achieved in FSIDig over the investigated time period after the incubation of microcapsule containing extracts compared to pure ethanolic extracts. A higher concentration of polyphenols at intestinal phase is synonymous to higher resorption and hence its bioavailability. However, right after the release from microcapsules, only $20 \%$ released polyphenolic contents found to face the fate of degradation due to which only $80 \%$ of initially added polyphenolic were measured from intestinal fluids. Comparatively, at gastric phase ( $\mathrm{pH} 1.2)$, degradation of polyphenolic compounds occurred during the first $20 \mathrm{~min}$ in pure ethanolic extracts, and in case of microcapsules, the degradation rate of polyphenols was higher than the release rate of polyphenolic compounds during the first 20 min (Fig. 4). At gastric phase, all polyphenolic compounds released from microcapsules after $20 \mathrm{~min}$ with less degradation rate afterwards. 
With respect to matrix solution (reference), no degradation was noticed while incubation of non-gelled matrix solution at gastric level $(\mathrm{pH}$ 1.2) throughout the investigated time period. Conversely, almost $30 \%$ of initially available polyphenols lost during the incubation in FSIDig (pH 6.8), but this degradation of polyphenols began after the 20 min (with no initial observed degradation) of incubation which continued afterwards up to $40 \mathrm{~min}$ (Fig. 4). The addition of extracts/microcapsules into the intestinal fluid did not change the $\mathrm{pH}$ of medium ( $\mathrm{pH}$ 6.8) which is indication of stabilization of polyphenolic compounds entrapped in the combinations of whey protein isolate and pectin at $\mathrm{pH}$ 6.8. These findings are in line with previous findings of various authors who described the interaction of polyphenolic compounds with different native proteins from neutral to alkaline $\mathrm{pH}$ a warranty to substantially slower down the degradation rate of entrapped bioactive compounds than in the protein free solution $[1,25,42,54]$. However, in whey proteins + pectin based microcapsules, the whey protein is thermally crosslinked and thus no or at least less interaction between native proteins and polyphenols occur. As many studies already demonstrated that addition of polysaccharide (i.e. pectin) capable of preventing/mitigating the protein-polyphenolic interaction $[32,50]$. Therefore, the observed stabilizing effect in the FSIDig, can be referred to diffusive and time based release of stable polyphenols from the microcapsules.

\section{Acute toxicity}

The microbial lipids production by MC have been commercialize since last three decades and still hold the "GRAS (Generally recognized as safe)" status [41] since no metabolite and lipids from MC showed any toxicological sign for human consumptions as trial were carried out by United States Food \& Drug regulatory authority and other European regulatory authorities [41]. The commercial production of orange-yellow food grade natural colorant ( $\beta$-carotene) from $\mathrm{MC}$ is in its developmental stage also considered safe for human consumption [14]. Since the utilization of very same mycelia of MC, grown under the same fermentation conditions as for lipids and $\beta$-carotene production, for natural antioxidant production so one can established the fact that natural antioxidant production from MC would be safe too for application in food and pharmaceutical industry. To further strengthen this hypothesis acute oral toxicity studies were carried out with albino (male) mice $(n=21)$. In vivo toxicity appraisal is the initial toxicological evaluation of medicinal plant/marine/microbe derived products by histopathology and oral acute toxicity studies. In vivo toxicity outcomes will be important to conclusively judging the safety of medicinal plant/microbial derived products.
However, acute toxicity studies do not detect the effects of plant/marine/microbe derived products on central nervous system, cardiovascular, and pulmonary/respiratory systems, and must be evaluated separately prior declaring safe for human consumption. Moreover, there are still some concerns related to extrapolating the animal data to human, but studies showed mice give more credible prediction for human acute lethal dose than rats [52]. All the experiments were preceded according to strict guidelines of OECD [37]. The albino mice $(11 \times 1=11)$ were orally administered with best declared microcapsule $\left(\mathrm{T}_{\mathrm{A}}\right)$ /crude ethanolic extracts and were monitored (for any toxic sign and mortality) from very start after the oral administration till the end of specified period as mentioned above. Compared to controls $(10 \times 1=10)$,

Table 3 The observations of general appearance, behavior, organ-to-body weight index, and biochemical parameters of serum for control and treated groups of albino mice

\begin{tabular}{lll}
\hline Observations & Control group & Treated group \\
\hline $\begin{array}{l}\text { General observations } \\
\text { Skin and fur }\end{array}$ & Normal & Normal \\
Eyes & Normal & Normal \\
Mucous membranes & Normal & Normal \\
Behavioral changes & Normal & Normal \\
Salivation & Normal & Normal \\
Urination (color) & Normal & Normal \\
Lethargy & Normal & Normal \\
Sleep & Normal & Normal \\
Diarrhea & Not found & Not found \\
Coma & Not found & Not found \\
Tremors & Not found & Not found \\
Organ-to-body weight index ${ }^{1}(\%)$ & & \\
Kidney & $1.11 \pm 0.17$ & $1.53 \pm 0.23^{\mathrm{a}}$ \\
Heart & $0.57 \pm 0.07$ & $1.23 \pm 0.2^{\mathrm{a}}$ \\
Liver & $4.8 \pm 0.39$ & $6.87 \pm 0.47^{\mathrm{a}}$ \\
Lung & $0.79 \pm 0.04$ & $1.53 \pm 0.11^{\mathrm{a}}$ \\
Spleen & $0.67 \pm 0.09$ & $1.77 \pm 0.1^{\mathrm{a}}$ \\
Body weight & $22.7 \pm 0.8$ & $24.7 \pm 1.3^{\mathrm{a}}$ \\
Biochemical parameters of serum & & \\
TBIL ( $\mu$ mol/L) & $1.2 \pm 0.2$ & $0.9 \pm 0.1$ \\
ALT (U/L) & $17.7 \pm 4.4$ & $18.1 \pm 5.1$ \\
AST (U/L) & $81.4 \pm 3.7$ & $79.1 \pm 5.2$ \\
ALP (U/L) & $86.3 \pm 9.6$ & $87.7 \pm 11.3$ \\
\hline a Gener 0 ) & & \\
\hline
\end{tabular}

a General observations were taken through the treatment period started right after oral administration of specific doses

b Control groups (treatment without crude extract)

c Treated groups (treatment with $2000 \mathrm{mg} / \mathrm{kg}$ crude extract)

1 Organ body index $=$ (organ weight $\times 100)$ /body weight; microcapsule $\left(\mathrm{T}_{\mathrm{A}}\right) /$ crude ethanolic extracts was administered to mice at a dose of $2000 \mathrm{mg} / \mathrm{kg}$; values are mean $\pm S D(n=21)$ at $5 \%$ level of significance $\left({ }^{*} p<0.05\right)$ 
Table 4 Antioxidant activity, nutritional and color parameters evaluation of (a) control cottage cheese in comparison with cottage cheeses enriched with (b) free microbial extracts, and (c) microencapsulated extracts

\begin{tabular}{|c|c|c|c|c|c|c|}
\hline \multirow[t]{2}{*}{ Parameters } & \multicolumn{2}{|c|}{ Control cottage cheese } & \multicolumn{2}{|c|}{ Cottage cheese with free extracts } & \multicolumn{2}{|c|}{$\begin{array}{l}\text { Cottage cheese } \\
\text { with microencapsulated } \\
\text { extracts }\end{array}$} \\
\hline & 0 day & 7th day & 0 day & 7th day & 0 day & 7th day \\
\hline \multicolumn{7}{|l|}{ Antioxidant activity* } \\
\hline DPPH radical scavenging activity & $>180$ & $>180$ & $83.1 \pm 8.7 b$ & $124.2 \pm 4.4 a$ & $111.8 \pm 3.5 \mathrm{a}$ & $73.7 \pm 6.4 c$ \\
\hline Reducing power & $145 \pm 4.9$ & $129.3 \pm 7.5$ & $76.7 \pm 5.3 c$ & $113 \pm 6.1 a$ & $91.6 \pm 5.3 b$ & $63.5 \pm 4.8 d$ \\
\hline \multicolumn{7}{|l|}{ Nutritional values } \\
\hline Ash (g/100 g fw) & $1.5 \pm 0.07$ & $1.68 \pm 0.06$ & $1.33 \pm 0.03$ & $1.86 \pm 0.08$ & $1.58 \pm .08$ & $1.45 \pm 0.05$ \\
\hline Fat (g/100 g fw) & $16.2 \pm 0.06$ & $15.9 \pm 0.1$ & $15.58 \pm 0.04$ & $16.78 \pm 0.1$ & $16.54 \pm 0.13$ & $17.03 \pm 0.1$ \\
\hline Protein (g/100 g fw) & $12.3 \pm 0.04 b$ & $12.1 \pm 0.08 b$ & $12.6 \pm 0.04 a$ & $12.2 \pm 0.1 \mathrm{a}$ & $12.3 \pm 0.05 \mathrm{ab}$ & $12.6 \pm 0.12 \mathrm{ab}$ \\
\hline Carbohydrates (g/100 g fw) & $1.15 \pm 0.09$ & $1.97 \pm 0.2$ & $1.25 \pm 0.04$ & $2.04 \pm 0.2$ & $1.24 \pm 0.11$ & $1.72 \pm 0.15$ \\
\hline Energy (kcal/100 g fw) & $204.9 \pm 1.3 a$ & $204.3 \pm 0.8 a$ & $194.8 \pm 2.4 a$ & $217.1 \pm 1.7 a$ & $191.3 \pm 1.7 b$ & $201.1 \pm 2.1 b$ \\
\hline SFA (relative \%) & $68.3 \pm 0.3 b$ & $71.1 \pm 0.4 b$ & $73.4 \pm 0.3 a$ & $71.7 \pm 0.6 a$ & $70.6 a \pm b$ & $71.6 \pm 1.2 b$ \\
\hline MUFA (relative \%) & $26.3 \pm 0.4 a$ & $24.2 \pm 0.3 a$ & $22.3 \pm 0.2 b$ & $23.4 \pm 0.1 b$ & $25.5 \pm 0.11 a$ & $24.7 \pm 0.17 a$ \\
\hline PUFA (relative \%) & $5.3 \pm 0.13$ & $4.5 \pm 0.4$ & $4.6 \pm 0.34$ & $4.6 \pm 0.05$ & $4.7 \pm 0.07$ & $4.8 \pm 0.2$ \\
\hline \multicolumn{7}{|l|}{ Color parameter } \\
\hline$L^{*}$ & $91.3 \pm 0.43$ & $91.4 \pm 0.39$ & $92.5 \pm 0.25$ & $90.1 \pm 0.75$ & $91.5 \pm 0.26$ & $90.4 \pm 0.3$ \\
\hline$a^{*}$ & $2.4 \pm 0.11 a$ & $2.1 \pm 0.12 \mathrm{a}$ & $1.7 \pm 0.0 b$ & $1.5 \pm 0.07 b$ & $1.8 \pm 0.02 b$ & $1.6 \pm 0.04 b$ \\
\hline$b^{*}$ & $9.6 \pm 0.08 b$ & $11.3 \pm 0.2 b$ & $10.23 \pm 0.14 a b$ & $12.31 \pm 0.41 \mathrm{ab}$ & $11.6 \pm 0.34 a$ & $11.5 \pm 0.11 \mathrm{a}$ \\
\hline
\end{tabular}

Antioxidants activity was expressed in $\mathrm{EC}_{50}(\mathrm{mg} / \mathrm{mL}) . L^{*}, a^{*}$, and $b^{*}$ represents the color parameters. In each row, different letters (a-d) correspond to significance $(p<0.05)$ among the treatments whereas data without letter is considered non-significant. Results are expressed as $3 n \pm S . D$

no obvious signs of distress, toxicity, and mortality were observed at a dose of $2000 \mathrm{mg} / \mathrm{kg}$ by gavage. Physically, body, eyes, fur, and skin were normal without significant variations in behavior, food intake and water consumption. The body weight of treated mice exhibited non-significant rise as compared to control, which evidenced the negligible toxicity on growth of mice (Table 3). Generally, the alternation of body weight and internal organ weight is indicator of possible toxicity, and unwanted variations in the physiological, metabolic, and pathophysiological index respectively. Generally, a decrease $(\geq 10 \%)$ in body weight (from initial weight) is symbolic to adverse effect of a drug/product [43]. Furthermore, statistically, weak significant increase in absolute and relative organto-body-weight was witnessed (Table 3) which needs to be investigated separately. Following organ weight index, hematopoietic system serves as an important index of the pathological and physiological status [2]. After 14 days of oral administration of microcapsule $\left(\mathrm{T}_{\mathrm{A}}\right)$ /crude ethanolic extracts, no substantial variation in the serum levels of total bilirubin level (TBIL), alkaline phosphatase (ALP), alanine aminotransferase (ALT), and aspartate aminotransferase (AST) were detected, hence, confirming the non-toxic nature of microcapsule $\left(\mathrm{T}_{\mathrm{A}}\right) /$ crude ethanolic extracts (Table 3 ).

\section{Cottage cheese with and without microencapsulated microbial extracts}

Table 4 comprehensively describes the outcomes of cottage cheese prepared with free and micro-capsular extracts in comparison with control cheese. The in vitro bioactivity of cheese in terms of antiradical potential and reducing power revealed that incorporation of free microbial extracts resulted in higher antioxidant power initially ( $t=$ day 0$)$ which progressively decreased up to 7 th day due to possible degradation of antioxidants. In case of microcapsules, the bioactivities of cheese was at lower at the beginning $(t=$ day 0$)$ which reached its peak value on the last day $(t=$ day 7$)$ of analysis. This later rise in antioxidant capacity can be credited to protection aided from microencapsulation together with sustained release pattern.

With respect to nutritional and color evaluation, the incorporation of either free or microencapsulated microbial extracts did not produce substantial variations in the ash, carbohydrate, fat, and polyunsaturated fatty acids (PUFA) contents of cottage cheese (Table 4). However, a weakly significant amount of saturated fatty acids (SFA) and monounsaturated fatty acids (MUFA) was observed in both treated (free extract and microcapsule added) groups of cottage cheese. These slightly higher contents of SFA and MFA might be dedicated to the shield offered 
Table 5 Sensorial appraisal of cottage cheese by selected panel of consumers

\begin{tabular}{lccc}
\hline Sensory attributes & Control cottage cheese & Cottage cheese with free extracts & $\begin{array}{l}\text { Cottage cheese } \\
\text { with microencapsulate } \\
\text { extracts }\end{array}$ \\
\hline Texture liking & $8.06 \pm 0.9$ & $7.8 \pm 0.5$ & $7.2 \pm 0.4$ \\
Flavour/taste liking & $7.9 \pm 0.8$ & $7.2 \pm 0.4$ & $7.06 \pm 0.2$ \\
Overall liking & $7.16 \pm 0.4$ & $6.8 \pm 0.2$ & $6.93 \pm 0.1$ \\
\hline
\end{tabular}

In each row, different letters $(a-d)$ correspond to significance $(p<0.05)$ among the treatments whereas data without letter is considered non-significant. Results are expressed as $3 n \pm$ S.D

by the added extracts in cottage cheese against the degradation. However, all the nutritional values obtained were found to be in the range of reference values for this kind of cottage cheese. In general, the incorporation of extracts (either free or microencapsulated) introduced slight (but non-significant) variations in the profile of protein, SFA and MUFA only when compared with control cottage cheese. In the appraisal of color, the addition of extracts failed to produces marked variations in $L^{*}$ and $a^{*}$ while comparing with control group.

\section{Sensory appraisal}

The impact of adding free or microencapsulated microbial extracts in cottage cheese on consumer liking was assessed. The best declared microcapsule (whey protein + pectin) was chosen for this analysis. The consumers' appraisals were summarized in Table 5. The simple ANOVA results clearly depicted no obvious variations in the liking values of three kinds of cottage cheeses. The consumers literally did not perceive any kind of difference regarding taste/flavor affecting the liking of cottage cheeses. Consumers rated the three kinds of cheeses alike with reference to taste/flavor liking. Hence the addition of free or microencapsulated microbial extracts did not brought about the variations in the consumers expected and actual physical and sensorial cues.

This work concluded the possibility of microencapsulating the microbial ethanolic extracts of MCWJ11 with the combinations of selected biopolymers. 5\% WPHG $+5 \%$ pectin $\left(\mathrm{T}_{\mathrm{A}}\right)$ showed higher scores with respect to physico-chemical, powder flowing, retention of bioactive compounds, and hence encapsulating properties over the other three treatments. The in vitro digestibility assays of microcapsule powder $\left(\mathrm{T}_{\mathrm{A}}\right)$ showed improved, targeted and time-dependent release of bioactive compounds with minimal degradation and hence loss even under adverse digestion conditions. Acute oral toxicity experimentation with albino mice confirmed the non-toxic nature of microcapsule $\left(\mathrm{T}_{\mathrm{A}}\right)$ /crude ethanolic extracts at a dose of $2000 \mathrm{mg} / \mathrm{Kg}$ since no aberrant variation in general appearance, behavior and biochemical parameters of serum were observed. The fortification of cottage cheese with microencapsulated microbial extract produced non-significant variations with respect to cottage cheese with added free microbial extracts in physico-chemical, nutritional, compositional, and sensory analysis terms.

\section{Acknowledgements \\ The authors are pleased to state that this work was supported by the National Natural Science Foundation of China (Grant Nos. 31670064 and 31271812) and the TaiShan Industrial Experts Programme. This work was also financially supported by the European Union's Horizon 2020 research and innovation programme under the Marie Skłodowska-Curie grant agreement No 754432 and the Polish Ministry of Science and Higher Education, from financial resources for science in 2018-2023 granted for the implementation of an international co-financed project.}

\section{Authors' contributions}

YS supervised this work. AH and SAH performed all the experimental work. AH wrote this manuscript. HARS edited and reviewed the whole manuscript and provided suggestions to main authors about overall research plan and antioxidant activities. ZM, SN, SU and YW assisted in the formulation of cottage cheese and their subsequent analysis. All authors read and approved the final manuscript.

\section{Conflict of interests}

Authors declare no competing interests.

\section{Author details}

${ }^{1}$ Colin Ratledge Center for Microbial Lipids, School of Agriculture Engineering and Food Science, Shandong University of Technology, Zibo, People's Republic of China. ${ }^{2}$ Clinical Research Center, Medical University of Bialystok, Jana Kilińskiego Street 1, 15-089 Białystok, Poland. ${ }^{3}$ Department of Biology, South Texas Center of Emerging Infectious Diseases (STCEID), University of Texas, San Antonio 78249, USA. ${ }^{4}$ Key Laboratory of Environment Correlative Dietology, Ministry of Education, Huazhong Agricultural University, Wuhan 430070, Huazhong, People's Republic of China. ${ }^{5}$ UQ Diamantina Institute, Translational Research Institute, Faculty of Medicine, The University of Queensland, 37 Kent Street Woolloongabba, Brisbane, QLD 4102, Australia. ${ }^{6}$ Department of Food, Nutrition, Dietetics and Health, Kansas State University, Manhattan, KS 66506, USA. ${ }^{7}$ Centre for Chemistry and Biotechnology, School of Life and Environmental Sciences, Deakin University, Pigdons Road, Waurn Ponds, VIC 3216, Australia.

Received: 16 September 2019 Accepted: 13 May 2020

Published online: 22 May 2020

\section{References}

1. Ackermann M (2010) Studien zum Verhalten von Anthocyanen aus Heidelbeeren im Humanstoffwechsel - Stabilisierung und Bindung durch Proteine. Dissertation, Julius-Maximilians-Universität Würzburg 
2. Adeneye AA, Ajagbonna OP, Adeleke TI, Bello SO (2006) Preliminary toxicity and phytochemical studies of the stem bark aqueous extract of Musanga cecropioides in rats. J Ethnopharmacol 105:374-379

3. Aguiar J, Estevinho BN, Santos $L$ (2016) Microencapsulation of natural antioxidants for food application — the specific case of coffee antioxidants: a review. Trends Food Sci Technol 58:21-39. https://doi. org/10.1016/j.tifs.2016.10.012

4. AOAC (2012) Official methods of analysis of AOAC international. In: Horwitz G, Latimer (eds) (19th ed), AOAC International, Washington

5. AOAC (2005) Official methods of analysis of AOAC international. In: Horwitz G, Latimer (eds) (18th ed), AOAC International, Gaithersburg

6. Aulton ME (2004) Translation of pharmaceutics: the science of dosage form design. Elsevier, España

7. Bogdanowicz KA, Tylkowski B, Giamberini M (2013) Preparation and characterization of light-sensitive microcapsules based on a liquid crystalline polyester. Langmuir 29:16011608

8. Bouayed J, Deusser H, Hoffmann L, Bohn T (2012) Bioaccessible and dialysable polyphenols in selected apple varieties following in vitro digestion vs. their native patterns. Food Chem 131:1466-1472

9. Cai YZ, Corke H (2000) Production and properties of spray-dried Amaranthus betacyanin pigments. J Food Sci 65(7):1248-1252

10. Cano-Chauca M, Stringheta PC, Ramos AM, Cal-Vidal J (2005) Effect of the carriers on the microstructure of mango powder obtained by spray drying and its functional characterization. Innov Food Sci Emerg Technol 6:420-428

11. Chen C, Chi YJ, Xu W (2012) Comparisons on the functional properties and antioxidant activity of spray-dried and freeze-dried egg white protein hydrolysate. Food Bioprocess Technol 5:2342-2352

12. Cilek B, Luca A, Hasirci V, Sahin S, Sumnu G (2012) Microencapsulation of phenolic compounds extracted from sour cherry pomace: effect of formulation, ultrasonication time and core to coating ratio. Eur Food Res Technol 235(4):587-596. https://doi.org/10.1007/s00217-012-1786-8

13. Clifford MN (2000) Anthocyanins - nature, occurrence and dietary burden. J Sci Food Agric 80:1063-1072

14. Dufossé $L$ (2016) Pigments, Microbial. Reference module in life sciences

15. European pharmacopoeia 7.0, Chapter 2.9.36: Powder flow, 2010, p 308

16. Ezhilarasi PN, Indrani D, Jena BS, Anandharamakrishnan C (2013) Freeze drying technique for microencapsulation of Garcinia fruit extract and its effect on Bread quality. J Food Eng 117:513-520

17. Fang Z, Bhandari B (2010) Encapsulation of polyphenols - a review. Trends Food Sci Technol 21:510-523

18. Ferrari CC, Germer SPM, Alvim ID, Vissotto FZ, Aguirre JM (2012) Influence of carrier agents on the physicochemical properties of blackberry powder produced by spray drying. Int J Food Sci Technol 47:1237-1245

19. Fernandes RVB, Borges SV, Botrel DA (2014) Gum arabic/starch/maltodextrin/inulin as wall materials on the microencapsulation of Rosemary essential oil. Carbohydr Polym 101:524-532

20. Gallo L, Llabot JM, Allemandi D, Bucala' V, Piña J (2011) Influence of spraydrying operating conditions on Rhamnus purshiana (Ca'scara sagrada) extract powder physical properties. Powder Technol 208:205-214

21. Gunasekaran S, Ko S, Xiao L (2007) Use of whey proteins for encapsulation and controlled delivery applications. J Food Eng. https://doi. org/10.1016/j.jfoodeng.2006.11.001

22. Hameed A, Hussain SA, Hua Z, Song Y, Zang L, Suleria HAR (2019) Antioxidant activity of polyphenolic extracts of filamentous fungi Mucor circinelloides (WJ11); extraction, characterization and stability of food emulsions. Food Biosci. https://doi.org/10.1016/j.fbio.2019.100525

23. Hameed A, Hussain SA, Yang J, ljaz MU, Liu Q, Suleria HAR, Song Y (2017) Antioxidants potential of the filamentous fungi (Mucor circinelloides). Nutrients 9:1101. https://doi.org/10.3390/nu9101101

24. Hussain SA, Hameed A, Khan MAK, Zhang Y, Zhang H, Garre $V$, Song $Y$ (2019) Engineering of fatty acid synthases (FASs) to boost the production of medium-chain fatty acids (MCFAs) in Mucor circinelloides. Int J Mol Sci 20:786. https://doi.org/10.3390/ijms20030786

25. Jing P, Giusti MM (2005) Characterization of anthocyanin-rich waste from purple corncobs (Zea mays L.) and its application to color milk. J Agric Food Chem 53:8775-8781

26. Jacobsen C, Sørensen ADM (2015) The use of antioxidants in the preservation of food emulsion systems. In: Handbook of antioxidants for food preservation. pp 392-298. http://dx.doi.org/10.1016/B978-1-78242 $-089-7.00016-6$
27. Julkunen-Tiitto R (1985) Phenolic constituents in the leaves of northern willows: methods for the analysis of certain phenolics. J Agric Food Chem 33(2):213-217. https://doi.org/10.1021/jf00062a013

28. Kapoor MP, Juneja LR (2009) Partially hydrolyzed guar gum dietary fiber. In: Cho SS, Samuel P (eds) Fiber ingredients: food applications and health benefits. CRC Press, Boca Raton, pp 70-120

29. Kaulmann A, Andre CM, Schneider YJ, Hoffmann L, Bohn T (2015) Carotenoid and polyphenol bioaccessibility and cellular uptake from plum and cabbage varieties. Food Chem 197(Pt A):325-332

30. Khan MAK, Yang J, Hussain SA, Zhang H, Garre V, Song Y (2019) Genetic modification of Mucor circinelloides to construct stearidonic acid producing cell factory. Int J Mol Sci 20:1683. https://doi.org/10.3390/ijms200716 83

31. Kuck LZ, Noreña CPZ (2015) Microencapsulation of grape (Vitis labrusca var. Bordo) skin phenolic extract using gum Arabic, polydextrose, and partially hydrolyzed guar gum as encapsulating agents. Food Chem 194:569-576. https://doi.org/10.1016/j.foodchem.2015.08.066

32. Le Bourvellec C, Renard CMGC (2012) Interactions between polyphenols and macromolecules: quantification methods and mechanisms. Crit Rev Food Sci Nutr 52(3):213-248

33. Macfie HJ, Bratchell N, Greenhoff K, Vallis L (1989) Designs to balance the effect of order of presentation and first-order carry-over effects in hall tests. J Sens Stud 4:129-148

34. Man YBC, Irwandi J, Abdullah WJW (1999) Effect of different types of maltodextrin and drying methods on physico-chemical and sensory properties of encapsulated durian flavor. J Sci Food Agric 79:1075-1080

35. Mandalari G, Bisignano C, Filocamo A, Chessa S, Saro M, Torre G, Faulks RM, Dugo P (2013) Bioaccessibility of pistachio polyphenols, xanthophylls, and tocopherols during simulated human digestion. Nutrition 29:338-344

36. Minekus M, Jelier M, Xiao JZ, Kondo S, Iwatsuki K, Kokubo S, Bos M, Dunnewind B, Havenaar R (2005) Effect of partially hydrolyzed guar gum (PHGG) on the bioaccessibility of fat and cholesterol. Biosci Biotechnol Biochem 69(5):932-938. https://doi.org/10.1271/bbb.69.932

37. OECD (1995) OECD guidelines for the testing of chemicals, repeated dose 28-day oral toxicity study in rodents. 407

38. Oidtmann J, Schantz M, Mäder K, Baum M, Berg S, Betz M et al (2012) Preparation and comparative release characteristics of three anthocyanin encapsulation systems. J Agric Food Chem 60(3):844-851

39. Paini M, Aliakbarian B, Casazza AA, Lagazzo A, Botter R, Perego P (2015) Microencapsulation of phenolic compounds from olive pomace using spray drying: a study of operative parameters. LWT Food Sci Technol 62(1):177-186. https://doi.org/10.1016/j.lwt.2015.01.022

40. Parthasarathi SC, Anandharamakrishnan S (2016) Enhancement of oral bioavailability of vitamin E by spray-freeze drying of whey protein microcapsules. Food Bioprod Process 100:469-476

41. Ratledge C (2013) Microbial oils: an introductory overview of current status and future prospects. OCL 20(6):D602. https://doi.org/10.1051/ ocl/2013029

42. Rawel HM, Kroll J, Hohl UC (2001) Model studies on reactions of plant phenols with whey proteins. Nahrung-Food 45:72-81

43. Raza M, Al-Shabanah OA, El-Hadiyah TM, Al-Majed AA (2002) Effect of prolonged vigabatrin treatment on haematological and biochemical parameters in plasma, liver and kidney of Swiss albino mice. Sci Pharm 70:135-145

44. Reis FS, Heleno SA, Barros L, Sousa MJ, Martins A, Santos-Buelga C (2011) Toward the antioxidant and chemical characterization of mycorrhizal mushrooms from Northeast Portugal. J Food Sci 76:C824-C830

45. Shui G, Leong LP (2006) Residue from star fruit as valuable source for functional food ingredients and antioxidant nutraceuticals. Food Chem 97(2):277-284

46. Sliwinski EL, Roubos PJ, Zoet FD, van Boekel MAJS, Wouters JTM (2003) Effects of heat on physicochemical properties of whey protein-stabilised emulsions. Colloid Surf B 31(1-4):231-242

47. Slinkard K, Singleton VL (1977) Total phenol analyses: automation and comparison with manual methods. Am J Enol Vitic 28:49-55

48. Smith H, Doyle S, Murphy R (2015) Filamentous fungi as a source of natural antioxidants. Food Chem 185:389-397. https://doi.org/10.1016/j.foodc hem.2015.03.134 
49. Tan SP, Kha TC, Parks SE, Stathopoulos CE, Roach PD (2015) Effects of the spray-drying temperatures on the physiochemical properties of an encapsulated bitter melon aqueous extract. Powder Technol 281:65-75

50. Taira S, Ono M, Matsumoto N (1997) Reduction of persimmon astringency by complex formation between pectin and tannins. Postharvest Biol Technol 12(3):265-271

51. Tonon RV, Brabet C, Hubinger MD (2008) Influence of process conditions on the physicochemical properties of açai (Euterpe oleraceae Mart.) powder produced by spray drying. J Food Eng 88(3):411-418

52. Walum E, Nilsson M, Clemedson C, Ekwall B (1995) The MEIC program and its implications for the prediction of acute human systemic toxicity. In: Goldberg AM, van Zutphen LFM (eds) Alternative methods in toxicology and the life sciences, vol 11. Mary Ann Liebert, New York, pp 275-282
53. Wong TW, Colombo G, Sonvico F (2011) Pectin matrix as oral drug delivery vehicle for colon cancer treatment. AAPS Pharm Sci Tech 12:201-214

54. Zheng N, Bucheli P, Jing H (2009) Effects of casein- and whey proteindextran conjugates on the stability of bog bilberry anthocyanin extract. Int J Food Sci Technol 44:1452-1458

\section{Publisher's Note}

Springer Nature remains neutral with regard to jurisdictional claims in published maps and institutional affiliations.

\section{Submit your manuscript to a SpringerOpen ${ }^{\circ}$ journal and benefit from:}

- Convenient online submission

- Rigorous peer review

- Open access: articles freely available online

- High visibility within the field

- Retaining the copyright to your article

Submit your next manuscript at $\boldsymbol{\sim}$ springeropen.com 